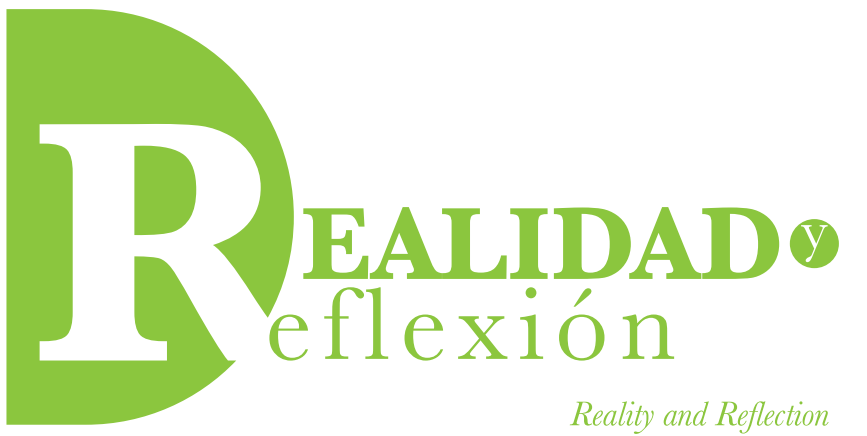

ISSN 1992-6510

Año 15, N 42, San Salvador, El Salvador, Centroamérica. Revista Semestral Julio-Diciembre 2015

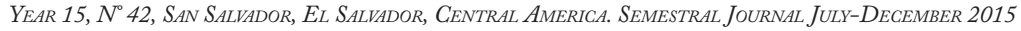

\title{
Regulación jurídico-penal de los delitos sexuales en Honduras ${ }^{1}$
}

\section{Criminal legal regulation of sexual crimes in Honduras}

\author{
Hazel Jasmín Bolaños Vásquez \\ Doctora en Derechos Humanos y Derecho Penal por la Universidad de Zaragoza. \\ Licenciada en Ciencias Jurídicas por la Universidad Centroamericana José Simeón Cañas. \\ Investigadora Asociada, ICTI-UFG \\ hazelbolanosv@gmail.com
}

\section{RESUMEN}

El artículo hace un estudio de los delitos que protegen el bien jurídico libertad e indemnidad sexual en la legislación hondureña, comenzando con el análisis del contexto social del país en relación con la violencia sexual, para luego analizar la actual legislación constitucional y secundaria que busca erradicar este tipo de violencia. En específico, se analiza a la legislación penal que sanciona la vulneración de los bienes jurídicos en estudio, para identificar si en los tipos penales persisten estereotipos de género que puedan incidir de forma negativa en la protección del derecho de las víctimas a ser tratadas con igualdad.

Tras el análisis de los distintos tipos penales se evidencia que, a pesar de las diversas reformas realizadas a la legislación penal hondureña, es necesario revisar y modificar la configuración de algunos tipos penales, principalmente los delitos de violación y estupro, así como el suprimir otros tipos penales cuya regulación podría inducir al juzgador a vincular dichos delitos con conceptos como el honor y el pudor, como en los casos de los delitos de rapto e incesto. Asimismo, se advierte una falta de sistematización en los tipos penales, que afectan la aplicación de los mismos de forma integral.

Palabras clave: Libertad e indemnidad sexual, delitos sexuales, violencia sexual, Honduras. 


\begin{abstract}
The paper studies the offenses that protect the legal right to sexual indemnity and freedom in Honduran law, starting with the analysis of the social context of the country in relation to sexual violence, and then analyzes the current constitutional and secondary legislation that pursue to eradicate this violence. Specifically, the paper analyzes the criminal law that punish the violation of legal rights under study, for identify if in the criminal legislation persist gender stereotypes, which may have an adverse effect in the protection of the rights of victims to be treated with equality.

After analyzing the various offenses is evident that, despite the various reforms carried out to the Honduran criminal law, it is necessary to review and change the configuration of some crimes, especially the crimes of rape and statutory rape; and suppressing other offenses whose regulation might induce judges to link such crimes with concepts such as honor and shame, as in the cases of crimes of rape and incest. Also, exist a lack of systematization in the criminal regulation of sexual violence that affects its holistic application.
\end{abstract}

Keywords: Sexual freedom, sexual indemnity, sexual offenses, sexual violence, Honduras.

\section{Introducción}

Honduras es uno de los países del triángulo norte centroamericano con altos índices de violencia, la cual es potenciada por factores como la pobreza, exclusión, corrupción, tráfico, consumo de drogas, crimen organizado, inestabilidad laboral, entre otros. Estos altos índices de violencia, conjugados con la desigualdad de género -la cual en ciertos sectores es socialmente aceptada-, son los factores que potencian el ejercicio de la violencia sexual (Centro de Derechos de Mujeres, 2005; Dinys \& Padilla, 2012). En este sentido, el Sistema regional de indicadores Estandarizados de convivencia y Seguridad ciudadana (SES, 2011a), ${ }^{2}$ estimó que en Honduras la prevalencia de violencia sexual pasó del 4.6 en 2008 a 8.6 en 2010. ${ }^{3}$ Asimismo, reportó que la tasa de denuncias de delitos sexuales por cada 100,000 habitantes durante el año 2011 fue de 43.58, y para el año 2012 la tasa descendió mínimamente a $41.32 .{ }^{4}$ En el caso de los niños, niñas y adolescentes, víctimas de violencia sexual, los datos de la Oficina de Naciones Unidas contra la Droga y el Delito (UNODC) establecen que en el año 2012 la tasa de denuncias por cada 100,000 habitantes por delitos sexuales cometidos en perjuicio de niños, niñas y adolescentes, fue de 28.5 , trece puntos arriba del promedio de los 62 países estudiados por la UNODC (2015) en ese año.

Otro aspecto presente en los casos de violencia sexual es la culpabilización hacia las mujeres que sufren este tipo de violencia. Así, en el estudio realizado por Carías (2011) se encontró que siete de cada diez mujeres hondureñas considera que los hombres ejercen la violencia sexual porque ellas se visten de forma incorrecta; o que el acoso sexual sucede por sus "actitudes", porque

1 Este artículo presenta los avances de la investigación "Regulación jurídico-penal de los delitos sexuales en Centroamérica. Análisis desde la perspectiva de género", que lleva a cabo la autora con financiación de la Universidad Francisco Gavidia.

2 Proyecto a través del cual 20 países y dos ciudades capitales de Latinoamérica y el Caribe, se han asociado para mejorar y hacer comparables sus estadísticas sobre crimen y violencia. Información disponible en http://www.seguridadyregion.com/

3 Este indicador identifica la frecuencia de la violencia sexual registrada en la población en un período de 12 meses, representado por el cociente entre el número total de personas que responden afirmativamente las preguntas relacionadas con la violencia sexual en el período de 12 meses y el total de la población, expresada en porcentaje. Los datos son tomados de la Encuesta Regional de Violencia Sexual (SES, 2011a).

4 Mientras que para el año 2013 las autoridades hondureñas no reportaron datos. Esta tasa identifica el cociente entre el número total de denuncias por delitos sexuales y el total de la población, a mitad de periodo, expresada por 100,000 habitantes, por año. Los datos son tomados del Instituto Nacional de Estadísticas y del Ministerio Público (SES, 2011b). 
"provocan" a los hombres, porque son "coquetas" y por la forma de vestir, por drogarse o por andar sola (p. 29). En ese mismo sentido, Dinys \& Padilla (2012) establecen que en Honduras el $3.1 \%$ de mujeres justifica la violencia física del hombre hacia la mujer si esta se niega a tener relaciones sexuales, al mismo tiempo que un 2.3\% de hombres justifica la agresión física del hombre contra su pareja si ella no quiere tener relaciones sexuales en el momento en que el hombre lo desea.

Asimismo, la violencia sexual que sufren las mujeres hondureñas no se limita a actos que incluye la violencia física -tales como la violación o la agresión sexual- sino que también se ven expuestas a la violencia sexual simbólica. Así, Carías (2011) determinaron que de una muestra de 105 mujeres y 30 hombres en Tegucigalpa, nueve de cada diez mujeres mencionan que han recibido "piropos" en la calle; ${ }^{5}$ cinco de cada diez mujeres reportaron haber sido tocadas o manoseadas en la calle o en el transporte público. De igual forma, el 86.2\% de las mujeres manifestó tener miedo a ser víctimas de una agresión sexual, mientras que el 7\% de los hombres indicó sentir también ese tipo de miedo. Asimismo, la mitad de las mujeres encuestadas mencionaron haber sido víctimas de acoso a través de celulares o Internet. Igualmente, Honduras es un país de origen, tránsito y destino de víctimas de trata de personas con fines de explotación sexual,

\footnotetext{
5 No obstante, en general, las mujeres no consideran los piropos como una forma de violencia simbólica. Así, el $44 \%$ dijo que siempre le gustan los piropos; el 19\% cree que a veces pueden ser violencia; y el 37\% considera que los piropos sí son una forma de violencia. Las mujeres de este último grupo afirmaron que los piropos "son vulgares y ofenden", "dicen cosas feas y malas", "son una falta de respeto", "son agresivos", "son ofensivos", "insultos", "son morbosos y mal educados" (sic), "nos incomodan” (Carías, 2011, p. 18).
}

siendo la mayoría de víctimas mujeres, niñas y adolescentes. ${ }^{6}$ Así, en Honduras se explota sexualmente a mujeres, niñas y adolescentes tanto nacionales como a extranjeras de los países vecinos, tanto por nacionales como por extranjeras que ven a Honduras como un país de destino para el "turismo sexual". De igual forma la "rentabilidad" de este delito hace que muchos grupos de crimen organizado busquen nuevas víctimas para su explotación sexual. Asimismo, las migrantes latinoamericanas durante su tránsito por Honduras son especialmente vulnerables a ser víctimas de trata con fines de explotación sexual; y también las víctimas hondureñas de trata son llevadas a países de la región, tales como México, Guatemala, El Salvador y los Estados Unidos (U. S. Deparment of State, 2014).

No obstante de que la violencia sexual es una realidad en la coyuntura actual, en Honduras -al igual que en los otros países del triángulo norte centroamericano- esta asimismo fue utilizada por los grupos combatientes y las fuerzas del Estado como una práctica sistemática o generalizada que constituyó una estrategia de guerra, y cuyas víctimas fueron mayoritariamente mujeres jóvenes pertenecientes a grupos desprotegidos y excluidos de la sociedad (CLADEM, 2007). Incluso en la actualidad, también se reporta el uso de la violencia sexual por parte de militares y policías. Así, grupos de mujeres feministas denunciaron ante la Comisión Interamericana de Derechos Humanos que durante el golpe de Estado contra Manuel Zelaya, llevado a cabo

6 Asimismo, U.S. Department of State (2014) reporta que las poblaciones de lesbianas, gays, bisexuales y transexuales (LGBT) son también especialmente vulnerables a ser víctimas de trata con fines de explotación sexual. 
en 2009, se cometieron por parte de militares y policías abusos sexuales y violaciones hacia mujeres en resistencia. ${ }^{7}$

De igual manera, las organizaciones de mujeres en Honduras consideran que los índices de violencia sexual, especialmente aquella cometida por agentes del Estado contra niñas y jóvenes, se han incrementado después del derrocamiento del presidente Zelaya, puesto que el proceso de militarización sufrido por Honduras repercutió en un incremento alarmante de violencia sexual maquillada como delitos comunes cometidos por policías, militares y agentes estatales. Por ejemplo, en 2012 se registraron seis casos de violaciones sexuales por parte de militares a jóvenes menores de edad cuyas demandas no procedieron. ${ }^{8}$

De igual forma, la violencia sexual es un riesgo añadido que enfrentan las mujeres hondureñas durante los desastres naturales. ${ }^{9}$ En este sentido, se documentó durante la emergencia suscitada en el país por el huracán Mitch, violaciones y acoso contra mujeres, adolescentes y niñas que se encontraban refugiadas en los albergues. La denuncia de este tipo de violaciones contra la libertad e indemnidad sexual de las albergadas fue especialmente difícil de obtener cuando los vulneradores eran hombres conocidos por la familia de la víctima, o cuando las personas que dirigían los albergues no estaban sensibilizadas con esta problemática (Comisión Interamericana de Mujeres, 2012; Bradshaw \& Arenas, 2004).

\footnotetext{
7 Ver Comisión Interamericana de Derechos Humanos (2009), pp. 2 parr. 9; 136-139.

8 Zamora Márquez (2013).

9 Dinys \& Padilla (2012), p. 42.
}

En cuanto a los grupos vulnerables, huelga apuntar el caso de las afrodescendientes, que suelen ser víctimas de violencia sexual, no solo por los hombres de sus comunidades, sino también por hombres de otros grupos étnicos, por sus patronos o por agentes estatales (Foro Internacional de Mujeres Indígenas, 2006). Asimismo, las mujeres detenidas o en prisión son un grupo vulnerable, principalmente en los últimos años en los que la población encarcelada se ha incrementado. ${ }^{10}$ En estos contextos de sobrepoblación carcelaria, las mujeres se encuentran particularmente expuestas a la violencia sexual, sobre todo cuando no hay una desagregación por sexo de la población encarcelada o cuando los policías, agentes de seguridad o guardias de las prisiones o centro de detención para mujeres son hombres (Dammert \& Zúñiga, 2008). Así, estos agentes de autoridad en ocasiones abusan sexualmente de las mujeres durante su detención o cuando las acompañan a las audiencias de sus juicios (Antony, 2007). En este sentido, el estudio realizado por Bähr (2005) sobre violencia contra las mujeres en Honduras evidenció que en los centros penitenciarios de Tela, San Pedro Sula y Puerto Cortés se habían registrado casos de abuso sexual contra las reclusas por parte del personal penitenciario.

Otro grupo especialmente vulnerable a la violencia sexual, es el de niñas y adolescentes, incluso en lugares como la familia o la escuela, en los que se esperaría que estuvieran a salvo de vulneraciones a sus derechos humanos. Así, lastimosamente, muchos de los casos de abuso infantil son cometidos por familiares; al

10 Por ejemplo, la población encarcelada ha pasado de 4,579 en 1990 a 11,545 en 2005 , lo que significa un incremento del $130 \%$ (Dammert \& Zúñiga, 2008). 
mismo tiempo, en algunos casos de explotación sexual, pornografía y prostitución infantil, sus perpetradores son miembros de la familia del niño, niña o adolescente vulnerado (Rodríguez et al., 2006). En cuanto al ámbito educativo, el abuso sexual que sufren las niñas y adolescentes suele estar ligado con las calificaciones o a la promoción de grado (Moreno, 2014).

Es válido destacar también la exposición a la violencia sexual que sufren, tanto las mujeres y adolescentes que tienen un vínculo de pareja con hombres asociados a pandillas o actividades de crimen organizado, como aquellas que pertenecen a estas organizaciones (Dinys \& Padilla, 2012). En el estudio realizado sobre maras y pandillas en Centroamérica, (Rodríguez et al., 2007), se estimó que en promedio existen 11 mujeres y 20 hombres por grupo de mara o pandilla, que tienen en promedio 30 miembros. Para el caso concreto de Honduras, los datos del Programa Nacional de Prevención, Rehabilitación y Reinserción Social reportaron que en el año 2011, había 872 mujeres miembros activas de maras y pandillas en 14 ciudades del país; ${ }^{11}$ las cuales tuvieron que enfrentar como rito de iniciación la violación sexual por parte de varios miembros del grupo. ${ }^{12}$

Asimismo, la vulneración a su libertad sexual es una constante durante el tiempo que pertenecen a la mara o pandilla, esta vulneración se manifiesta, en primer lugar, en la imposición de restricciones en relación con la elección de un compañero, el cual debe ser miembro de la mara

11 Esta cifra no incluye a las simpatizantes, novias o mujeres que no han pasado por los ritos de iniciación (The Assessment Capacities Project [ACAPS], 2014, p. 39). o pandilla. Las relaciones con personas que no pertenecen a la pandilla están prohibidas para las mujeres. De igual forma, el matrimonio solo es posible al interior de las pandillas (Rodríguez et al; 2007). ${ }^{13}$ En segundo lugar, se vulnera la libertad sexual de las mujeres pandilleras al imponérseles la obligación de realizar "favores sexuales” a los miembros que están en prisión, o como castigo hacia la mujer que hubiese rechazado la propuesta de un miembro. ${ }^{14} \mathrm{En}$ este sentido, en el estudio realizado sobre maras y pandillas, por Rodríguez et al., (2007), el 20\% de las 156 mareras/pandilleras centroamericanas entrevistadas manifestó haber tenido que acceder a un favor de tipo sexual con los compañeros o jefes de la mara o pandilla. ${ }^{15}$ En tercer lugar, estas mujeres también se encuentran expuestas a la violencia sexual por parte de terceros que tengan represalias contra la mara o pandilla (Bahr, 2005).

En cuanto a las denuncias por atentados contra la libertad e indemnidad sexual de las mujeres, el Ministerio Público de Honduras, en 2012

12 Asimismo, estos ritos incluyen el sometimiento a golpes para "ganarse el respeto" de la pandilla o mara (ACAPS, 2014, p. 39). En este sentido, un exmarero líder de la Mara Salvatrucha en Honduras manifiesta que "En el tiempo de antes como le digo pagaban ellas con darle sexo a todos, a trece personas, pero en este tiempo se les golpea como a un hombre" (Rodríguez et al., 2007, p. 39). Ver también Bahr (2005), pp. 22-25.

13 En este sentido, un exmarero líder de la Mara Salvatrucha en Honduras manifiesta "Las mujeres solo tienen que ser para el marido, no pueden tener relaciones sexuales con otro, con un paisa, con alguien que no es nada, porque también por eso las matan... la mujer no lleva muchas de ganancias, solo lleva de perder, más pérdidas que nosotros" (Rodríguez et al., 2007, p. 39).

14 Las mujeres en pandillas también son utilizadas para cometer delitos tales como extorsión, transporte de droga, mensajeras, visitar a los prisioneros y transportar elementos desde la prisión y hacia esta (ACAPS, 2014).

15 Asimismo, el 43\% indicó que las mujeres de la mara o pandilla eran víctimas de violencia física por parte de compañeros mareros (Rodríguez et al., 2007). 
reportó más de 16 mil denuncias por violencia contra las mujeres (Asociadas por lo Justo [JASS] et al., 2014), de las cuales 3,168 fueron interpuestas por mujeres víctimas de delitos sexuales, lo que equivale a 9 denuncias por delitos sexuales diariamente. E1 50\% de estas denuncias fueron por delito de violación sexual, seguido por el estupro, con un $16.4 \%$ y actos de lujuria, con el 12.9\% (Observatorio de Derechos Humanos de las Mujeres, 2014a). Mientras que durante el año 2013 se presentaron 2,851 denuncias por violencia sexual, lo que implica que cada 3 horas se interpuso una denuncia por violencia sexual en Honduras (JASS et al., 2014). Asimismo, entre los años 2010 y 2012 la cantidad de denuncias interpuestas ante el Ministerio Público, por los delitos de violación, violación especial y estupro permanecieron casi invariables. (Ver Gráfico 1)

Mientras que la Policía Nacional Civil [PNC], entre los años 2008 y 2010 registró un promedio de 3,975 casos de violencia sexual, de los cuales un aproximado del $80 \%$ de los casos fue cometido en niños, niñas y adolescentes (ver Tabla 1). Según los registro de la PNC, estos casos de violencia sexual contra la niñez y adolescencia comprenden los delitos de abusos deshonestos, acoso sexual, actos de lujuria, complicidad de violación, estupro, explotación sexual, incesto, pornografía infantil, proxenetismo, rapto, relaciones sexuales remuneradas, tentativa de rapto, tentativa de violación, trata de blancas, ultraje al pudor, violación y violación especial. ${ }^{16}$

16 De estos casos de delitos sexuales contra la niñez y la adolescencia, el estupro representó entre el 20 y el $23 \%$ del total de estos delitos en el período 2008-2010, registrándose 682 casos en el año 2008, 666 casos en el 2009 y 671 casos en el 2010 (Dinys \& Padilla, 2012, p. 32).
En el caso de las denuncias por violaciones sexuales, durante el período 2008-2010 se registró un promedio de 50 por cada 100,000 habitantes (Dinys \& Padilla, 2012) (ver Tabla 2). En cuanto a los casos de trata de personas, las autoridades reportaron haber realizado 38 investigaciones durante el año 2013, la mayoría de estas relacionadas con la finalidad de explotación sexual de niños, niñas o adolescentes (U. S. Deparment of State, 2014).

\section{Tabla 1}

Tasa de denuncias de violación sexual recibidas por la Policía Nacional Civil durante el período 2008-2010.

\begin{tabular}{c|c}
\hline Año & Tasa por $\mathbf{1 0 0 , 0 0 0 ~ H a b . ~}$ \\
\hline 2008 & 49,12 \\
\hline 2009 & 52,65 \\
\hline 2010 & 49,71 \\
\hline
\end{tabular}

Fuente: Fuente: Dinys \& Padilla (2012), p. 26.

Asimismo, el Instituto de Medicina Forense de Honduras, entre 2008 y 2010 registró un incremento de más del $100 \%$ de reconocimientos médicos por delitos sexuales, cuyas víctimas fueron en su mayoría mujeres -85.7\%- (ver Tabla 3), y de estas, el 81,2 \% eran niñas y adolescentes (Dinys \& Padilla, 2012). Este mismo Instituto realizó 2,648 evaluaciones médicas legales por violencia sexual en el año 2012 (Zamora, 2013); y de estas, de las que fueron solicitadas por requerimiento fiscal, la mitad corresponde a niñas menores de 14 años, y en 7 de cada 10 casos estos delitos fueron cometidos por hombres conocidos, familiares, expareja o pareja de la víctima (Observatorio de Derechos Humanos de las Mujeres, 2014a). Mientras que 


\section{Gráfico 1}

Denuncias por violencia, violación especial y estrupo a mujeres ante el ministerio público de Honduras, durante los años 2010-2012.

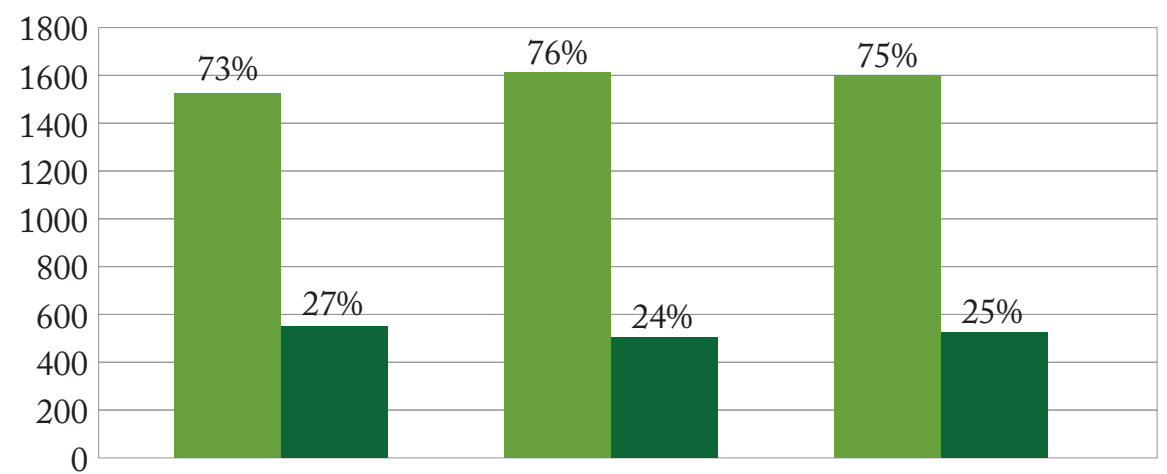

Violación y Violación especial Estrupo

Fuente: Observatorio de Derechos Humanos de las Mujeres (2014a), p. 5.

\section{Tabla 2}

Denuncias por violencia, violación especial y estrupo a mujeres ante el ministerio público de Honduras, durante los años 2010-2012.

\begin{tabular}{c|c|c|c}
\hline \multirow{2}{*}{ Años } & \multirow{2}{*}{ Total de delitos secuales } & \multicolumn{2}{|c}{ Delitos sexuales contra la niñez y adolescencia } \\
\cline { 3 - 4 } & & $\#$ & $\%$ \\
\hline 2008 & 3782 & 2966 & 78.4 \\
\hline 2009 & 4143 & 3289 & 79.4 \\
\hline 2010 & 4000 & 3317 & 82.9 \\
\hline
\end{tabular}

Fuente: Dinys \& Padilla (2012), p. 32.

en el año 2013 se realizaron 2,561 evaluaciones médicas legales por violencia sexual (ACAPS, 2014), que se estima corresponden al 70\% del total de las denuncias, puesto que no a todas las mujeres que presentan una denuncia se les realiza un examen médico (Zamora, 2013).
Mientras un monitoreo sobre la violencia contra las mujeres que fueron noticia en los medios de comunicación escrita de circulación nacional durante el año 2013, realizado por el Observatorio de Derechos Humanos de las Mujeres, identificó que en Honduras ocurrieron 529 hechos violentos que fueron noticia en la 
Tabla 3

Cantidad de reconocimientos por delitos sexuales según sexo de la víctima realizados por el Instituto de Medicina Forense durante el período 2008-2010.

\begin{tabular}{cc|c|cc}
\hline \multirow{2}{*}{ Sexo } & \multicolumn{3}{c}{ Año } & Total \\
\cline { 2 - 5 } & $\mathbf{2 0 0 8}$ & $\mathbf{2 0 0 9}$ & $\mathbf{2 0 1 0}$ & 761 \\
\hline Masculino & 151 & 210 & 400 & 4579 \\
\hline Femenino & 900 & 1467 & 2212 & 5340 \\
\hline Total & 1051 & 1677 & 2612 & \\
\hline
\end{tabular}

Fuente: Dinys \& Padilla (2012), p. 32.

prensa nacional durante ese año; de estos hechos violentos, el 15\% corresponde a violencia sexual. Asimismo, de 137 noticias sobre feminicidios, en el $8.7 \%$ de estas la conducta se había cometido precediendo actos de violencia sexual (Observatorio de Derechos Humanos de las Mujeres, 2014b).

De igual forma, hay que considerar la cifra oscura correspondiente a todas aquellas mujeres que no denuncian la violencia sexual que han sufrido y raramente buscan ayuda por miedo o desconocimiento (ACAPS, 2014). Por ejemplo, según el Centro de Derechos de Mujeres (2012), en los casos de las violaciones sexuales en Honduras, muchas veces la joven esconde el hecho por temor o vergüenza, porque la gente considera que ella es la culpable, que se lo buscó o que provocó esa violación. También las víctimas suelen callar, porque no encuentran apoyo ni en el colegio ni en la familia.

En el mismo sentido se manifiesta el informe realizado por Bott et al., (2013), el cual establece que en el período 2005-2006, del total de mujeres encuestadas el 29.3\% manifestó haber hablado con familiares o amigos después de haber recibido violencia por parte de su compañero íntimo, y un $18.9 \%$ solicitó ayuda institucional. Dentro de las razones que manifiestan las mujeres para no buscar ayudan están: la vergüenza, el temor a represalias, no saber adónde ir o no creer que alguien las ayudaría. En esta línea, ACAPS (2014) manifiesta que las supervivientes de violencia sexual de la región del triángulo norte centroamericano reciben escaso apoyo y la mayoría desconoce que puede acceder a asistencia y tratamiento. Asimismo, son pocos los hospitales que ofrecen asistencia integral.

De igual forma, la falta de denuncia por parte de las víctimas de violencia sexual también está asociada con la desconfianza en los operadores de justicia, especialmente en la Policía. Así, en el estudio realizado por Palacios (2008) en El Salvador, Honduras y Nicaragua las personas que participaron en los grupos focales realizados en la investigación manifestaron una total desconfianza en la honestidad, la eficiencia y la confidencialidad de la Policía al momento de denunciar un delito de abuso sexual. En esta misma línea, Muñoz (2011) manifiesta que las víctimas de violencia sexual también temen denunciar por la falta de apoyo en el seguimiento y el desarrollo del proceso 
legal, el cual además es "tortuoso y tendiente a revictimizar a las mujeres agredidas" (pp. 45-46). ${ }^{17}$

Por otra parte, los datos proporcionados por la Corte Suprema de Justicia [CSJ], en cuanto a los casos ingresados y las resoluciones dictadas por los juzgados, por delitos contra la libertad e indemnidad sexual, los números son mucho menores. Así, en el 2010, de los 926 casos recibidos por esta instancia, solo el 39\% había sido resuelto, es decir, recibieron una sentencia condenatoria o absolutoria. De igual forma, de este total de casos recibidos, 92 fueron por el delito de estupro, de los cuales el 47\% recibió una resolución (Dinys \& Padilla, 2012). En cuanto a la trata de personas, la Corte Suprema de Justicia reportó que durante el 2013 procesó 17 causas por trata de personas con fines de explotación sexual; no obstante, no se condenó a ningún imputado por este delito durante ese año. ${ }^{18}$

En cuanto a las estadísticas del Centro Electrónico de Documentación e Información Judicial [CEDIJ], analizadas por Carcedo (2012), en estas se refleja que de enero a setiembre de 2011, el total de sentencias condenatorias con relación a las absolutorias fue de $71.3 \%$, obteniendo Honduras un valor de 0.24 sobre 1 en el indicador "Porcentaje de denuncias de violencia sexual concluidas que son sancionadas" del Sistema de indicadores para evaluar desde la sociedad civil el cumplimiento estatal de la Convención de Belém do Pará. Asimismo, el

$17 \mathrm{El}$ autor también hace énfasis en factores tales como la falta de acceso al transporte, los escasos recursos para poder desplazarse y las largas distancias que deben de recorrer las víctimas desde su lugar de residencia, los cuales pueden también incidir en el acceso a la justicia.

18 No obstante, en marzo de 2014, se condenó a dos personas acusadas de trata con fines de explotación sexual, con una pena de 5 años de prisión y una multa (U. S. Deparment of State, 2014).
Observatorio de Derechos Humanos de las Mujeres (2014a) apunta que solamente el 29.5\% de todas las denuncias realizadas durante los años 2010-2013 por violencia sexual ingresó a los Juzgados de Letras de lo Penal, y de estos, solamente el $5.5 \%$ resultó en una sentencia condenatoria. Todos estos indicadores son preocupantes, en cuanto reflejan el restringido acceso de las víctimas y la impunidad de los delitos sexuales en el país.

En este sentido, Muñoz (2011) manifiesta la importancia que tiene el hecho de que el sistema de justicia realice una adecuada recolección de pruebas forenses, además de que se trabaje de forma conjunta con el sistema de salud, a fin de favorecer la disposición de la víctima para poder iniciar y finalizar el proceso legal, garantizándole su integridad personal y la no revictimización; todo esto con el objetivo de asegurar un fallo judicial satisfactorio para la víctima de violencia sexual.

Por todas estas situaciones comentadas supra, no es de extrañar que Honduras tenga un bajo índice de cumplimiento estatal de la Convención de Belém do Pará -0.46 sobre $1^{19}$ -, según el sistema de medición citado supra. Este sistema de medición toma en cuenta tres dimensiones, de la cuales la primera dimensión: "Coherencia con el espíritu de Belém do Pará" tiene como primer indicador "la definición de violencia", en el cual Honduras obtuvo 0.33 puntos sobre 1. E1 segundo indicador de esta

19 Lamentablemente, ninguno de los países de la región centroamericana llega a 0.60 , siendo el promedio regional de 0.50 . Esto significa que en la región hay una gran deuda pendiente con relación al cumplimiento de la Convención de Belém do Pará (Carcedo, 2012). 
dimensión es "El tratamiento de la violencia contra las mujeres como violación de derechos humanos", que mide el respeto que en la norma y la práctica tienen los Estados a considerar y tratar la violencia contra las mujeres como una violación de derechos humanos, otorgando medidas de protección en forma inmediata, no permitiendo la conciliación, no anteponiendo la unidad familiar u otros bienes jurídicos al derecho de las mujeres y niñas a vivir libres de violencia, y reconociendo en la práctica este derecho a todas las mujeres, en todas las circunstancias -entre otras, mujeres indígenas, trabajadoras sexuales, migrantes- y condiciones, y frente a cualquiera que sea el agresor. En este indicador Honduras obtuvo 0.31 sobre 1 puntos (Carcedo, 2012).

En conclusión, lamentablemente, la violencia sexual se ha convertido en una parte de la vida cotidiana de la mujeres hondureñas, pese a algunos esfuerzos que realiza el Gobierno hondureño, tales como la promulgación y la puesta en marcha del Segundo Plan de Igualdad y Equidad de Género de Honduras (2010-2022); así como el contar con una división policial especial contra el abuso, trata y explotación sexual infantil. Por lo tanto, es necesario continuar haciendo esfuerzos para minimizar, tanto los factores de riesgo asociados con la violencia sexual contra la mujer, así como garantizar el castigo de este tipo de conductas.

\section{Método}

Para realizar el estudio de los tipos penales que protegen el bien jurídico libertad e indemnidad sexual en la legislación hondureña se hizo uso de la metodología jurídico- doctrinal, siguiendo los métodos gramatical, hermenéutico y dogmático, confrontando a la legislación y a la jurisprudencia hondureña con la doctrina penal centroamericana, extranjera y la legislación internacional pertinente a los delitos de violencia sexual. Específicamente, en un primer momento se realizó una búsqueda en la legislación penal hondureña de aquellos delitos concernientes al bien jurídico en estudio. Tras delimitar y seleccionar estos tipos penales se procedió a analizarlos, utilizando como categorías de análisis la conducta típica, el sujeto activo y pasivo y la consecuencia jurídica de los delitos regulados en el Código Penal hondureño, Libro II Parte Especial, Título II Delitos contra la libertad e integridad física, psicológica y sexual de la personas, en la Ley Contra la Trata de Personas y en el Código de la Niñez y la Adolescencia. Asimismo, se utilizó el enfoque de género de forma transversal en el estudio, para determinar si las costumbres sociales y los estereotipos de género inciden en la redacción y aplicación de dichos tipos penales.

Tras el análisis de las categorías de los tipos penales en estudio se procedió a confrontar su contenido para interpretar su significado gramatical; asimismo, se analizó la interpretación jurisprudencial y dogmática realizada sobres dichos tipos penales, para luego proceder a confrontar estos análisis con los contenidos analizados (disputatio), para finalmente responder si la actual regulación de los delitos que protegen la libertad e indemnidad sexual en la legislación hondureña están configurados conforme a lo establecido en los instrumentos internacionales y la doctrina penal (vera solutio). 


\section{Resultados}

En cuanto a la legislación hondureña que protege el derecho a la indemnidad y libertad sexual, este encuentra protección, en primer lugar, en la Constitución de la República de Honduras de 1982. ${ }^{20}$ Así, el Artículo 1 de la Constitución establece que el Estado hondureño está constituido para asegurar a sus habitantes el goce de la justicia, la libertad, la cultura y el bienestar económico y social. En esta línea, en cuanto al derecho a la libertad, el Título III De las declaraciones, derechos y garantías, Capítulo I De las declaraciones, contiene sendas regulaciones para garantizar este derecho a los habitantes del país. Así, el Artículo 59 reconoce a la persona humana como el fin supremo de la sociedad y del Estado y declara inviolable la dignidad del ser humano. Asimismo, el Artículo 60 regula el principio de igualdad ante la ley; por lo tanto, todos los hombres y mujeres son iguales en derechos. Consecuentemente, se declara punible toda discriminación por motivo de sexo, raza, clase y cualquier otra lesiva, a la dignidad humana. En este mismo sentido, el Artículo 61 reconoce que la protección del derecho a la libertad -entre otros derechos- se garantizará, tanto a los hondureños como a los extranjeros residentes en el país.

De igual forma, en el Capítulo II De los derechos individuales, el Artículo 68 establece el derecho que tiene toda persona a que se respete su integridad física, psíquica y moral; y el Artículo 76 garantiza el derecho al honor, a la intimidad personal, familiar y a la propia imagen. Y en Capítulo IV De los derechos del niño, el

20 Decreto n. ${ }^{\circ} 131,11$ de enero de 1982. artículo 124 regula que las personas menores de edad deben ser protegidas contra toda forma de abandono, crueldad y explotación, prohibiendo la trata de niños, niñas o adolescentes.

Asimismo, la Constitución concede el rango de leyes de la República a los tratados internacionales celebrados por Honduras con otros Estados, y en el Artículo 18 se regula específicamente que en caso de conflicto entre el tratado o convención y la Ley prevalecerá el primero. Por lo tanto, también se encuentran vigentes para el país los diversos instrumentos relativos a la protección de la indemnidad y libertad sexual firmados por este.

Los derechos establecidos en la Constitución hondureña, en su vinculación con la libertad e indemnidad sexual, también son desarrollados por la legislación secundaria. En primer lugar, podemos mencionar al Código de Familia, ${ }^{21}$ el cual dentro de sus regulaciones de protección a la familia y a las instituciones vinculadas a ella, establece en el Artículo 108 numeral 2 que los casos de sentencia condenatoria por violación, estupro o rapto, cuando la fecha del hecho punible concuerde con la época de la concepción, se dará por presunta la paternidad del sujeto activo. En esta misma línea, el Artículo 214 estipula que el sujeto activo de los delitos de violación o estupro también estará obligado a dar alimentos al hijo nacido como consecuencia de la comisión del delito, siempre que la época de la concepción coincida con la del hecho punible, de acuerdo con las presunciones establecidas en la legislación hondureña. De igual forma, el Artículo 284 establece la consecuencia jurídica

21 Decreto $\mathrm{N}^{\circ}$ 76-84. Versión electrónica disponible en http://www. poderjudicial.gob.hn/juris/Leyes/Codigo\%20de\%20Familia\%20 (actualizada-07).pdf 
de remoción de tutela y pro tutela de aquellos que incitaren al pupilo a la corrupción o al delito. En complemento a la protección de la familia, el Estado hondureño, a través de la Ley contra la Violencia Doméstica (LVD), ${ }^{22}$ busca proteger la integridad física, psicológica, patrimonial y sexual de la mujer, contra cualquier forma de violencia por parte de su cónyuge, excónyuge, compañero, excompañero de hogar o cualquier relación afín a una pareja en la que medie haya mediado o no cohabitación, incluyendo aquellas relacionadas en las que se sostiene o se haya sostenido una relación sentimental. ${ }^{23}$ Para tal fin, el Artículo 1 de la Ley en comento establece que todo acto de discriminación y violencia doméstica contra la mujer debe ser sancionado de conformidad con esta Ley, la Convención Interamericana para Prevenir, Sancionar y Erradicar la Violencia Contra la Mujer, la Convención Internacional sobre la Eliminación sobre todas las formas de Discriminación contra la Mujer y otras que se suscribieren en el futuro sobre la materia.

En esta línea, el Artículo 2 de la LVD regula la obligación del Estado hondureño de adoptar las medidas que sean necesarias para prevenir, sancionar y erradicar la violencia doméstica contra la mujer, promoviendo y ejecutando, entre otras medidas, medidas interrelacionadas $\mathrm{y}$ globales que incluyan soluciones a corto $\mathrm{y}$ a largo plazo que coadyuven a la prevención y la erradicación de la violencia contra la mujer, así como todas aquellas que sean necesarias

22 Promulgada el 11 de septiembre de 1997. Reformas aprobadas por el Congreso Nacional el 1 de septiembre de 2005, publicadas en el Diario Oficial La Gaceta el 11 de marzo de 2006. Versión electrónica disponible en http://www.poderjudicial.gob.hn/juris/Leyes/Ley\%20 Contra\%201a\%20Violencia\%20Domestica\%20(actualizada-07).pdf

23 Artículo 1 Ley contra la Violencia Doméstica. para garantizar el pleno goce de los derechos y libertades de las mujeres.

En el Artículo 5 de la LVD se define la violencia doméstica como “Todo patrón de conducta asociado a una situación de ejercicio desigual de poder que se manifieste en el uso de la violencia física, psicológica, patrimonial y/o económica y sexual". El ejercicio desigual de poder al que hace alusión esta definición deber ser entendido como "Toda conducta dirigida a afectar, comprometer o limitar el libre desenvolvimiento de la personalidad de la mujer por razones de género”.

En cuanto a la protección de la libertad sexual, este artículo regula entre las formas de violencia doméstica a la violencia sexual, ${ }^{24}$ la cual constituye "Toda conducta que entrañe amenaza o intimidación que afecte la integridad o la autodeterminación sexual de la mujer, tal como las relaciones sexuales no deseadas, la negación a anticoncepción y protección, entre otras, siempre que dichas acciones no se encuentren tipificadas como delito en el Código Penal.” En esta línea, el Artículo 7 establece las sanciones administrativas en las que incurrirá el agresor que cometa actos de violencia doméstica, que no constituyan delitos en el Código Penal. Dichas sanciones son estas:

1. ${ }^{\text {a }}$ Prestación de servicios a la comunidad ${ }^{25}$ por el término de uno a tres meses, cuando la denuncia sea declarada con lugar.

25 El Artículo 7 de la LVD establece que la prestación de servicios a la comunidad deberá consistir en una profesión, oficio o actividad laboral diferente a la que ordinariamente realiza el denunciado y equivaldrá a una jornada de dos horas diarias, las que pueden ser en horas hábiles o inhábiles. Asimismo, para garantizar el cumplimiento de los servicios a la comunidad, será obligación del Juzgado competente remitir a la Alcaldía Municipal correspondiente el listado 


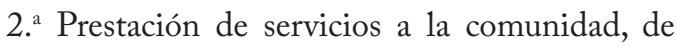
uno a tres meses, por el no acatamiento de uno o más de los mecanismos de protección impuestos, sin perjuicio de la pena a que hubiere lugar por el delito de desobediencia a la autoridad. ${ }^{26}$

En esta misma línea de protección de los derechos de las mujeres, en el año 2000 el Congreso Nacional de Honduras aprobó la Ley de igualdad de oportunidades para la mujer (LIOM), ${ }^{27}$ la cual establece que tanto hombres como mujeres nacen libres e iguales en derechos; ${ }^{28}$ asimismo, regula la obligación del Estado hondureño de realizar acciones para eliminar todo tipo de discriminación contra la mujer. ${ }^{29} \mathrm{E} 1 \mathrm{Art} .3 \mathrm{LIOM}$ define a la discriminación contra la mujer como "toda distinción, exclusión, o restricción basada en el sexo, que tenga por objeto o por resultado menoscabar o anular el reconocimiento, goce

de las personas sancionadas los primeros cinco días de cada mes. De igual forma, la Alcaldía Municipal correspondiente deberá informar obligatoriamente sobre la asistencia y el cumplimiento de la sanción impuesta al denunciado dentro del mismo término de cinco días. La misma obligación tendrán las Consejerías de Familia y cualquier otra institución pública en donde el denunciado cumpla las medidas o ejecute el servicio comunitario. El Artículo 7 también menciona la potestad que tiene la denunciante de informar al Juzgado competente o Juez de Ejecución sobre el incumplimiento de cualquier mecanismo de protección impuesto al denunciado.

26 Los Artículos 7 y 8 de la LVD establecen que en caso de desobediencia a las sanciones y/o medidas de seguridad impuestas al agresor, el juzgado competente deberá remitir de inmediato las actuaciones al Ministerio Público, dejando un extracto de lo actuado, para el ejercicio de la acción penal correspondiente. El delito de desobediencia se encuentra regulado en el Artículo 346 del Código Penal, el cual establece que "Quien desobedezca a una autoridad negándose abiertamente a dar el debido cumplimiento a sentencias, resoluciones u órdenes dictadas dentro de los límites de su competencia y revestidas de las formalidades legales, será penado con reclusión de uno (1) a tres (3) años".

27 Decreto $\mathrm{N}^{\circ}$ 34-2000. Versión electrónica disponible en http:// www.inam.gob.hn/index.php?option =com_content $\& v i e w=a r t i-$ cle\&id=100\&Itemid $=85$

28 Art. 1 LIOM.

29 Art. 2 LIOM. o ejercicio por la mujer, independientemente de su estado civil, sobre la base de igualdad del hombre y la mujer, de los derechos humanos y las libertades fundamentales en las esferas políticas, económica, social, cultural y civil o en cualquier otro aspecto". 30

En relación con el respeto de la libertad sexual de la mujer, el Artículo 13 LIOM establece la obligación del Estado de prevenir, combatir y erradicar la violencia doméstica e intrafamiliar, en los términos establecidos en la Ley Contra la Violencia Doméstica y el Código Penal. Asimismo, el Artículo 32 LIOM establece medidas de tipo preventivo al regular la obligación de los establecimientos educativos, de advertir a todo el personal que esté bajo su jurisdicción, las consecuencias legales que se derivan de abuso y acoso sexual, y de actuar de conformidad con la ley cuando se realicen actos de este tipo.

De igual forma, el Artículo 60 LIOM, regula el derecho de la trabajadora o servidora pública, víctima de acoso sexual por parte del patrono, de dar por terminada la relación de trabajo sin preaviso y sin responsabilidad de su parte, conservando el derecho a las prestaciones y las indemnizaciones legales como en el caso del despido injusto. Asimismo, se establece que cuando el que ejecutare el acoso, fuese un trabajador deberá procederse a su despido

\footnotetext{
30 Para dar cumplimiento al principio de no discriminación contra la mujer, el Art. 4 LIOM establece la obligación del Estado hondureño de garantizar la igualdad y la equidad entre hombres y mujeres, en el diseño y aplicación de políticas públicas para la ejecución y la coordinación de programas y proyectos. Asimismo, regula que la sociedad civil debe incluir la dimensión de género en las instancias de diálogo social para promover y fomentar las organizaciones que trabajan para, con y por la mujer.
} 
inmediato sin responsabilidad para el patrono o institución estatal. Al respecto, Pérez (2012) manifiesta que para que esta normativa tenga plena vigencia, debería introducirse expresamente la figura en el Código de Trabajo, sugiriendo su adición en el Artículo 96, que regula las prohibiciones a los patronos, o en el Artículo 114, que regula las causas justas que facultan al trabajador para dar por terminado el contrato de trabajo, sin preaviso y sin responsabilidad de su parte.

En nuestra opinión, coincidimos con Pérez (2012), ya que los supuestos de acoso sexual por parte del patrono se pueden entender contemplados, tanto en el artículo 96 numeral 9, en cuanto a la prohibición del patrono de ejecutar o autorizar cualquier acto que directa o indirectamente vulnere o restrinja los derechos que otorgan las leyes a los trabajadores, o que ofendan la dignidad de estos, así como en los supuestos del Artículo 114 letra b, que establece como causa justa para el trabajador o trabajadora para dar por terminado el contrato de trabajo cuando sea víctima de todo acto de violencia, malos tratamientos, o amenazas graves inferidas por el patrono, dentro o fuera del servicio, o inferidas dentro del servicio por los parientes, representantes o dependientes del patrono, con el consentimiento o la tolerancia de este. De igual forma, la letra j del mismo Artículo regula como causa justa para dar por terminado el contrato de trabajo, cuando el patrono cometa o reciba cualquiera violación grave de las obligaciones o prohibiciones especiales que le incumben de acuerdo con los Artículos 95 y 96 del Código de Trabajo; no obstante, sería más garante para el derecho de las mujeres a vivir libres de violencia sexual, el contar con una mención expresa sobre la prohibición hacia el patrono de cometer actos de tono sexual, tales como contactos físicos e insinuaciones, observaciones de tipo sexual, exhibición de pornografía y exigencias sexuales, verbales o de hecho, que den motivos suficientes al trabajador o trabajadora como para creer que su negativa podría causarle problemas en el trabajo, en la contratación o el ascenso, o creando un medio de trabajo hostil. ${ }^{31}$

En el ámbito de las personas menores de edad, el Código de la Niñez y la Adolescencia ${ }^{32}$ en el Título que regula los derechos y libertades de los niños, regula entre los derechos generales de la niñez y adolescencia el derecho a la dignidad. ${ }^{33}$ Este derecho es regulado de manera concreta en el Capítulo III del citado Título, referente al derecho a la dignidad, a la libertad y a la opinión, el cual en el Artículo 24 específica que la dignidad forma parte de la personalidad de los niños; por lo tanto, es deber de todas las personas velar por el respeto de tal derecho y de proteger a los niños contra cualquier trato inhumano, violento, aterrorizante, humillante o destructivo.

Para concretizar esta protección, el Libro II del Código en comento regula la protección de los niños. Así, en el Artículo 93 se establece la obligación del Gobierno hondureño de adoptar las medidas que sean necesarias para prevenir y sancionar las amenazas o las violaciones a los derechos de los niños. En relación con la

31 Ver Art. 11 Recomendación General núm. 19 de la Convención para la eliminación de todas las formas de discriminación contra las mujeres (CEDAW). Versión electrónica disponible en http://www. ipu.org/splz-e/cuenca10/cedaw_19.pdf

32 Decreto $\mathrm{N}^{\circ}$ 73-96. Versión electrónica disponible en http://www. poderjudicial.gob.hn/juris/Codigos/C\%C3\%B3digo\%20de $\% 20$ la\%20Ni\%C3\%B1ez\%20y\%201a\%20Adolescencia\%20(09).pdf

33 Art. 11. 
protección contra la violencia sexual, el Artículo 100 establece que la Secretaría de Estado en los Despachos de Gobernación y Justicia, por medio de las gobernaciones políticas y de las corporaciones municipales, serán las responsables de adoptar las medidas que sean necesarias para evitar y combatir la prostitución infantil.

Asimismo, el Artículo 141 establece que un niño, niña o adolescente será considerado en situación de abandono o de peligro cuando -entre otros supuestos- sea objeto de acciones u omisiones que tiendan a pervertir su personalidad, tales como promover o facilitar la prostitución o cualquier otra forma de abuso sexual; las ofensas al pudor; las exhibiciones sexuales impropias; la exposición de desnudos que ofendan la decencia pública; la entrada a garitos, casas de prostitución $\mathrm{u}$ otros sitios inapropiados; el acoso sexual; las incitaciones deshonestas o corruptoras, incluso aquellas que se manifiestan por medio de preguntas y proposiciones irrespetuosas $y$, en general, todas las incitaciones que afecten el desarrollo psicológico, la dignidad, la autoestima y el sano juicio de los niños. ${ }^{34}$

En esta línea, el Artículo 97 establece la prohibición de que los niños y las niñas ingresen o permanezcan en moteles, casas de prostitución y clubes nocturnos u otros análogos, obligando a los propietarios de dichos establecimientos a dar a conocer esta prohibición mediante aviso visible. La infracción de esta disposición conlleva una sanción administrativa regulada en el Artículo 99, consistente en el cierre de su establecimiento por una semana, la primera vez, por dos semanas, la segunda vez, y con la cancelación definitiva

34 Art. 141 letra ch). del permiso de funcionamiento si comete una tercera o ulterior infracción. ${ }^{35}$

De igual forma, el Artículo 123 establece la prohibición de que los niños menores de dieciocho años realicen trabajos que afecten su moralidad, en especial, el trabajo en casas de lenocinio y demás lugares de diversión donde se consuman bebidas alcohólicas. Asimismo, establece la prohibición de contratar a niños, niñas o adolescentes para la reproducción de escenas pornográficas, muertes violentas, apología del delito u otras labores semejantes. En consonancia, con esta prohibición el Artículo 124 regula la obligación de cualquier persona que tenga conocimiento de la participación de niños en cualquier tipo de trabajo prohibido, de informar a la Secretaría de Trabajo y Previsión Social para la aplicación de los correctivos y sanciones a que haya lugar.

Finalmente, resulta relevante citar la Ley de Migración y Extranjería de Honduras, la cual en su Artículo $42^{37}$ establece un reconocimiento especial de la condición de refugiado para aquellas personas que hayan huido de su país porque su vida, seguridad o libertad se han visto amenazadas por sufrir persecución mediante violencia sexual u otras formas de persecución de género, basada en violaciones de derechos humanos consagrados, en instrumentos internacionales. Asimismo, el

35 El Artículo 99 también establece que las sanciones serán impuestas por la autoridad que haya expedido los permisos de funcionamiento.

36 Decreto n. 208-2003. La Gaceta, 3 de marzo, 2004, texto disponible en http://www.poderjudicial.gob.hn/CEDIJ/Leyes/ Documents/LEY\%20DE\%20MIGRACI\%C3\%93N\%20Y\%20 EXTRANJERIA\%20\%2809\%29.pdf

37 Numeral 3, letra e). 
Artículo 39 de la ley en comento permite que la Dirección General de Migración y Extranjería conceda permisos especiales de permanencia en el país hasta por un máximo de cinco años, a extranjeros víctimas de Trata de Personas, ${ }^{38}$ entre otros supuestos contemplados en dicho Artículo. En cuanto a la legislación penal que protege a los bienes jurídicos libertad e integridad sexual, en primer lugar, podemos mencionar el Código Penal de Honduras, ${ }^{39}$ vigente desde 1984. Durante su vigencia ha sufrido importantes reformas que atañen a los bienes jurídicos en comento. La primera reforma fue la realizada mediante el Decreto $191-96,{ }^{40}$ en la cual se modificaron más de 200 artículos, y en lo referente a la protección de la libertad e indemnidad sexual, concretamente, se introdujo el tipo penal de acoso sexual. ${ }^{41}$ En el año de 1997 se realizó una segunda reforma al Código Penal mediante el Decreto 59-97, ${ }^{42}$ reforma que para Pérez $(2012)^{43}$ vino a ser una "contrarreforma" al Decreto 191-96, ante la presión de varios sectores que se sintieron afectados por la severidad de las penas establecidas para ciertos delitos.

La tercera importante reforma realizada al Código Penal por medio del Decreto $234-2005,{ }^{44}$ significó

38 Numeral 5, letra a).

39 Decreto n.o 144-83 del Congreso Nacional, de fecha 23 de agosto de 1983. Publicado en el Diario Oficial "La Gaceta" número 24,264 en fecha 12 de marzo de 1984.

40 Decreto emitido el 31 de octubre de 1996 y publicado en el Diario Oficial 28,182 de fecha 8 de febrero de 1997.

41 Cuya denominación fue modificada y su pena fue disminuida en reforma posterior, mediante el Decreto 59- 97. Ver Pérez (2012), p. 45.

42 Decreto emitido el 8 de mayo de 1997 y publicado en el Diario Oficial 28,281 en fecha 10 de junio del mismo año.

43 p. 45.

44 Decreto emitido el 1 de septiembre de 2005 y publicado en el Diario Oficial 30,920 de fecha 4 de febrero de 2006. una actualización a los delitos contra la libertad e indemnidad sexual, para que estos estuvieran acordes a lo establecido en los instrumentos internacionales suscritos por el Estado hondureño, tales como el Convenio 182 de OIT sobre las peores formas de trabajo infantil, la Convención sobre Delincuencia Organizada Transnacional y su Protocolo Facultativo sobre venta de niños, prostitución infantil y la utilización de niños en pornografía. En esta línea, se introdujeron principalmente delitos que sancionaban la explotación sexual comercial, adicionando un nuevo capítulo para contener este tipo de delitos. Asimismo, en esta reforma se ampliaron los tipos penales de violación, actos de lujuria, estupro e incesto (Pérez, 2012).

Así, tras estas reformas, actualmente el Código Penal hondureño regula en el Libro II Parte Especial, Título II, los delitos contra la libertad y la integridad física, psicológica y sexual de la personas, que contiene dos capítulos, el I, que regula los delitos de violación, estupro, ultraje al pudor,rapto; y elCapítulo II, que regula los delitos de explotación sexual comercial. En cuanto a la denominación del Título, nos parece que este debería reformarse, pudiendo denominarse "Delitos contra la libertad e indemnidad sexual de las personas", determinando de esta manera el bien jurídico protegido en los delitos de violencia sexual, a la vez que se eliminarían los problemas de interpretación o significación que generan los conceptos "pudor" o "rapto".

En cuanto a los delitos regulados en el Capítulo I del Título en estudio, el Artículo 140 sanciona el delito de violación, como el acceso carnal -ya sea por vía vaginal, anal o bucal- con persona de uno u otro sexo mediante violencia o amenaza 
de ocasionarle al sujeto pasivo, al cónyuge de este o compañero de hogar, o a uno de sus parientes dentro del cuarto grado de consanguinidad o segundo de afinidad, un perjuicio grave e inminente. La sanción establecida para este delito es la pena de diez a quince años de reclusión. Llama la atención el hecho de que el legislador hondureño haya restringido taxativamente el tipo de amenaza que debe recibir el sujeto pasivo del delito de violación, en cuanto a que dicha amenaza debe estar dirigida hacia la víctima o su cónyuge, o compañero de hogar, o a uno de sus parientes dentro del cuarto grado de consanguinidad o segundo de afinidad.

Consideramos que esta restricción no es adecuada, en tanto que el sujeto pasivo también podría recibir otro tipos de amenazas para acceder a una relación sexual no consentida, por ejemplo, amenazas de ocasionar un perjuicio grave e inminente a una tercera persona con la que no se posea un vínculo de los establecidos en el tipo penal, pero que tenga una relación cercana con la víctima, o incluso se podrían dar situaciones de amenazas a personas desconocidas por la víctima, pero que le lleven a cumplir con la condición impuesta - en esta caso la violaciónpor solidaridad, es decir, para evitar un mal a un tercero (Jareño, 2010). Por ejemplo, en el caso del sujeto pasivo que toma como rehén a un sujeto desconocido para la víctima, pero que amenaza con lastimar e incluso matar a este tercer sujeto si el sujeto pasivo no accede a sostener una relación sexual con el sujeto activo.

Asimismo, deberían contemplarse dentro del tipo penal regulado en el Artículo 140 los supuestos de amenazas de fuerza sobre las cosas o vis in rebus, en tanto que se utilice la amenaza de emplear una fuerza con capacidad para dañar los objetos sobre los que recae, con el fin de afectar la libertad de decisión de la víctima. Por ejemplo, en el caso de la legislación española, el tipo penal de amenazas (Art. 169 Código Penal español) contempla la conducta de amenazar al sujeto pasivo, a su familia u otras personas con las que esté íntimamente vinculado, con ejecutar un mal que constituya uno de los delitos regulados en el catálogo establecido en el Artículo 169; dentro de este catálogo se encuentran los delitos contra el patrimonio. En este sentido, sería válido considerar dentro de los supuestos de amenazas del Artículo 140 del Código Penal hondureño a aquellas realizadas al sujeto pasivo ofreciéndole destruir un objeto con tal de impedir su utilización (Caruso, 2006). En definitiva, la vis in rebus también puede provocar la intimidación de una víctima de violación (Monge, 2005).

Por lo tanto, lo que sería importante considerar en estos casos es que la amenaza efectuada a la víctima posea la entidad suficiente como para provocar que esta acceda a la relación sexual, en tanto que dicha amenaza ponga en peligro la tranquilidad de la víctima y su libertad de decisión. Por consiguiente, la valoración sobre la idoneidad de la amenaza tendría que adoptarla el juez, tomando en cuenta las características concretas del sujeto pasivo y realizando el análisis de idoneidad de la amenaza con parámetros objetivos (Jareño, 2010).

El inciso tercero y el cuarto del Artículo 140 regulan el subtipo agravado de violación con una pena de quince a veinte años de reclusión, supuesto que se cumplirá cuando se realice el acceso carnal con persona de uno u otro sexo 
sin mediar violencia o amenaza, concurriendo cualquiera de las circunstancias siguientes:

1) Cuando la víctima sea menor de catorce años de edad;

2) Cuando la víctima se halle privada de razón o de voluntad, o cuando por cualquier causa no pueda oponer resistencia;

3) Cuando el sujeto activo para cometer el delito de violación intencionalmente disminuya o anule la voluntad de la víctima utilizando para ello sustancias psicotrópicas o estupefacientes, incluyendo alcohol, o si cometió la violación encontrando al sujeto pasivo en la situación anterior;

4) Cuando el sujeto activo esté encargado de la guarda o custodia de la víctima y se valga de su condición de autoridad para tener acceso a la misma; $y$

5) Cuando el sujeto activo, a sabiendas de que es portador del Síndrome de Inmuno Deficiencia Adquirida/ Virus de Inmuno Deficiencia Humano (SIDA/VIH), o una enfermedad contagiosa de orden sexual incurable, cometa la violación.

También se consideran violación agravada los siguientes supuestos:

1) Cuando la violación se cometa por más de una persona;

2) Cuando la violación se cometa por alguien reincidente;
3) Cuando la víctima esté embarazada o quede embarazada como producto de la violación; o

4) Cuando la víctima sea mayor de setenta años.

En relación con la regulación de delito de violación, Pérez (2012) añade que las organizaciones de mujeres en Honduras han manifestado la necesidad de establecer un tipo específico para la violación marital o de pareja, con el objeto de hacer visible el problema y la preocupación del Estado en torno a una conducta históricamente tolerada y poco denunciada. Asimismo, de esta forma se remarcaría el derecho de la mujer a la igualdad en las relaciones de matrimonio o de convivencia. Para tal fin, el autor hace tres sugerencias: en primer lugar, se podría agregar un párrafo al tipo básico de violación contemplado en el Artículo 140, para denotar que el delito se puede cometer dentro de matrimonio o relación de hecho; un segundo mecanismo sería listarlo como una de las circunstancias agravantes que configuran el tipo de violencia intrafamiliar del Artículo $179-\mathrm{B} ;{ }^{46} \mathrm{y}$

46 Dicho delito se encuentra actualmente configurado de la siguiente manera: Art. 179 B.- Será sancionado con reclusión de dos (2) a cuatro (4) años quien haga objeto de malos tratamientos de obra a su cónyuge, ex-cónyuge, concubina o ex-concubina o a la persona con quien haya procreado un hijo, en cualquiera de las circunstancias siguientes:

a) Penetre en la morada de la persona o en el lugar en que esté albergada o depositada para consumar el hecho;

b) Le infiera grave daño corporal;

c) Realice la acción con arma mortífera aunque no hay actuado con la intención de matar o mutilar;

d) Actúe en presencia de menores de edad;

e) Induce, incita u obliga a la persona a consumir drogas, estupefacientes u otras sustancias psicotrópicas o embriagantes;

f) Hace también objeto de malos tratos a un menor de edad; y,

g) Utilice como pretexto para restringir su libertad que la víctima padece de enfermedad o de defecto mental.

Lo dispuesto en este artículo se entenderá sin perjuicio de la pena que corresponda a los otros delitos en que incurra. 
un tercero podría ser establecer un delito propio, para lo cual habría que configurar los elementos personales y objetivos del nuevo tipo.

El Código Penal hondureño también tipifica en su Artículo 141 el delito de actos de lujuria. No obstante, el tipo penal es impreciso, puesto que no define qué se entenderá por actos de lujuria. Así, el Artículo en comento literalmente establece que "comete actos de lujuria, quien valiéndose de las condiciones o empleando los medios indicados en el artículo anterior (delito de violación) hace víctima a otra u otras personas de actos de lujuria distintos del acceso carnal". La consecuencia jurídica estipulada para este delito es de cinco a ocho años de reclusión.

En el inciso segundo del mismo Artículo se regula un subtipo agravado, que corresponde a la conducta de cometer actos de lujuria en sujeto pasivo menor de catorce 14 años, o que adolezca de una enfermedad mental o desarrollo psíquico incompleto o retardado; en estos casos el tipo penal especifica que el delito se comete incluso cuando el sujeto pasivo haya consentido el acto. También se incluye dentro del subtipo agravado cuando la conducta se cometa sobre sujeto pasivo al que se le se haya privado de razón o voluntad, o cuando el sujeto pasivo no pueda oponer resistencia. La consecuencia jurídica del subtipo agravado es la pena principal incrementada en un medio. De igual forma, el inciso tercero del Artículo 141 establece otro subtipo agravado, el cual consiste en cometer actos de lujuria mediante la introducción de objetos o instrumentos de cualquier naturaleza en los órganos sexuales $\mathrm{u}$ otros orificios naturales o artificiales que simulen los órganos sexuales del cuerpo del sujeto pasivo. Dicha conducta se sanciona con pena de reclusión de diez a quince años.

Como se puede advertir, este tipo penal es impreciso al determinar la conducta típica que debe cometer el sujeto activo, y no contiene verbos rectores claros, lo cual representa una vulneración al principio de legalidad, además de dejar al criterio interpretativo del juez qué se debe entender por "actos de lujuria". No obstante, dado que el tipo penal establece que el sujeto activo deberá cometer "actos de lujuria distintos del acceso carnal”, se puede interpretar que el acto de lujuria constituye un acto de naturaleza sexual ejecutado mediante violencia o amenaza sobre el sujeto pasivo. Asimismo, hacemos la misma crítica realizada supra respecto a la limitación en el tipo de amenazas que debe sufrir el sujeto pasivo para que se configure el tipo penal.

Similar situación sucede con el Artículo 142, el cual contiene el tipo penal de estupro, limitándose a establecer que "El estupro de una persona mayor de catorce (14) y menor de dieciocho (18) años prevaliéndose de confianza, jerarquía o autoridad, se sancionará con pena de seis (6) a ocho (8) años de reclusión. Cuando el estupro se cometa mediante el engaño se sancionara con pena de cinco (5) a siete (7) años de reclusión”. Nuevamente, observamos cómo el legislador penal no describe la conducta típica del delito de estupro, seguramente, valiéndose de la definición que, tanto la doctrina como la jurisprudencia, le han dado a este delito. Así, doctrinariamente se entiende por estupro la conducta de tener relaciones sexuales con acceso carnal con una persona menor de edad, pero con edad para consentir sexualmente, cuando dicho acceso carnal se realiza por medio de un consentimiento 
viciado, ya sea prevaliéndose de una situación de superioridad o mediante engaño del sujeto pasivo (Goenaga, 1997); Santibáñez, 2010). ${ }^{47}$

En esta línea se ha pronunciado la jurisprudencia hondureña, por ejemplo, en la Sentencia de Casación CP-392-09 emitida por la Sala de lo Penal de la Corte Suprema de Honduras, al resolver el recurso planteado por el recurrente, cuestionando que la definición contenida en el Artículo 142 del Código Penal no precisa los elementos objetivos de dicho tipo penal, la Sala de lo Penal manifestó que no obstante la falta de precisión en describir una conducta determinada, el Artículo 142 establece que sanciona el "estupro" como conducta prohibida y regula las modalidades de estupro. Asimismo, manifestó la Sala que "En cuanto a la conducta prohibida (estupro), es aceptado en la doctrina [que esta] se entienda [como] un acto de 'acceso carnal', y de conformidad a lo establecido en el artículo de la ley penal sustantiva ya referido, concurre cuando la víctima tiene los límites de edad señalados en el mismo, y si el sujeto activo lo hace prevaliéndose de alguna de las modalidades taxativamente señaladas $[. .$.$] , siendo permitido$ [...] que el juzgador pueda $y$, necesariamente deba realizar de manera racional con el fin de la norma su función de intérprete, para poder aplicar correctamente el derecho a los hechos

47 Mientras que el Diccionario de la Real Academia Española define Estupro como "(Del lat. stuprum).

1. m. Der. Coito con persona mayor de 12 años y menor de 18 , prevaliéndose de superioridad, originada por cualquier relación o situación.

2. m. Der. Acceso carnal con persona mayor de 12 años y menor de 16, conseguido con engaño.

3. m. Der. Por equiparación legal, algún caso de incesto.

4. m. Antiguamente, coito con soltera núbil o con viuda, logrado sin su libre consentimiento". develando la finalidad y el sentido inmanente de la norma que se aplica" (Sala de lo Penal de la Corte Suprema de Justicia, 2011). De igual forma, el Tribunal de Sentencia de Juticalpa, en sentencia emitida el 15/12/2008, interpretó que "el imputado [...] es responsable del abuso sexual, producido en la menor [...], abuso que se configura como ESTUPRO que se produce por el hecho de haberla penetrado vía vaginal, a una persona mayor de catorce años y menor de dieciocho cuando haya mediado para ello abuso de confianza" (Tribunal de Sentencia de Juticalpa, 2008).

Mientras que el Artículo 143 regula el delito de incesto, el cual consiste en el "acceso carnal con ascendientes o descendientes, entre hermanos, o en relación entre adoptante y adoptado, con madrastra o padrastro, cuando la víctima sea mayor de dieciocho (18) años”. Dicha conducta es sancionada con una pena de cuatro a seis años de reclusión y se establece como condición de procesabilidad la presentación de querella de la parte ofendida o su representante legal. Mientras que el inciso segundo del Artículo en comento establece la regulación de un subtipo agravado, cuando el sujeto pasivo de la conducta de incesto sea una persona mayor de catorce y menor de dieciocho años de edad; en estos casos, la pena principal se agravará en un medio de la pena.

Resulta cuestionable la regulación del subtipo agravado, en cuanto que esta conducta típica también podría encajarse en otras conductas reguladas en el mismo Capítulo I relativo a la Violación, Estupro, Ultraje al pudor, Rapto. Por ejemplo, en el supuesto de que el sujeto activo tuviese acceso carnal con descendiente, hermano/a, adoptado $/ \mathrm{a} ;{ }^{48}$ puede coincidir 
que a la vez el sujeto activo sea el encargado de la guarda o custodia del sujeto pasivo y se valga de su condición de autoridad para tener acceso carnal con este, configurándose a su vez el delito de violación agravada estipulado en el Artículo 104 núm. 4), principalmente porque en los supuestos de violación especial -tal como hemos visto supra- no requieren que concurra la violencia o amenaza sobre el sujeto pasivo para que se configure el tipo penal. Similar situación sucede cuando el sujeto activo tuviese acceso carnal con ascendiente, hermano/a, adoptante, madrastra o padrastro mayor de setenta 70 años, en el sentido de que también se configuraría el supuesto regulado en el Artículo 140 inciso final, si el acceso carnal se ejecutare con violencia o intimidación.

Y es que, por el hecho de que el Artículo 143 regule como condición de procesabilidad que la parte ofendida inicie la querella, de esta condición se infiere que la persona que acude al Ministerio Público a denunciar que ha sido víctima del delito de incesto, se siente atacada y/o vulnerada en su libertad sexual. En este sentido, cabría cuestionarse ¿qué es lo que distingue al delito de incesto del delito de violación o estupro? Si lo que se castiga es el acceso carnal con un pariente, pero se establece como condición que sea la parte ofendida la que inicia la querella, inevitablemente estaremos ante casos en los que el acceso carnal se ha realizado sin el consentimiento de la víctima, pues de otra forma no acudiría a denunciar. Asimismo, la condición de procesabilidad conlleva otro peligro, el cual es que una persona que haya sido víctima del delito

48 Llama asimismo la atención de que el tipo penal no contemple como sujetos pasivos a los hijastros o hijastras, siendo que sí menciona expresamente a los padrastros o madrastras. de incesto no acuda a denunciar por temor al sujeto activo y, en estos casos -que podrían ser propios delitos de violación más que de incestoestaríamos propiciando la impunidad, en cuanto que una tercera persona no podría interponer la querrella, ni tampoco el Ministerio Público podría actuar de oficio.

Por ejemplo, en la sentencia de casación CP484-11 (Sala de lo Penal de la Corte Suprema de Justicia, 2013) se puede advertir las diferentes interpretaciones que puede conllevar la inadecuada regulación de los tipos penales de violación e incesto. Así, en dicha sentencia la Sala de lo Penal de la Corte Suprema de Justicia hondureña conoce del Recurso de Casación por Infracción de Ley interpuesto por el Defensor Público del imputado, acusado por haber violado a su hija, menor de edad, la cual narró que el día lunes nueve de octubre del año dos mil salió de su casa en compañía de su padre partiendo hacia la comunidad de Palcaca, al llegar a dicha comunidad su padre la abrazó por la espalda "diciéndole hoy si vamos a tener relaciones sexuales quitándole el short y el blúmer a la fuerza abusando sexualmente, dejándole mucho dolor en todas sus piernas y parte íntima, ordenándole ponerse la ropa intentándola violar nuevamente de regreso a su casa”. Por los hechos narrados, el Fiscal del Ministerio Público presentó acusación por los delitos de Violación e Incesto. No obstante, el Juzgado de Letras Departamental de la Sección Judicial de Puerto Lempira, departamento de Gracias a Dios, resolvió declarar culpable al imputado, del delito de Violación en grado de ejecución de tentativa, subsumiendo el delito de Incesto en el mismo acto de Tentativa de Violación "por no haber habido acceso carnal", condenando al imputado a la pena de cuatro años de reclusión. 
Como podemos observar, mientras que el fiscal consideró aplicar un concurso real entre los dos delitos, el juez de la causa consideró que existía un concurso de leyes. Y en el ámbito doctrinario, Pérez (2012) considera que, haciendo una interpretación sistemática del Código Penal, si la víctima de incesto es menor de 14 años se consumaría una violación especial, según la segunda parte del Artículo 140 del Código Penal. Estas diversas interpretaciones pueden deberse a la confusión que genera la tipificación de dos delitos que regulan conductas demasiado similares. Asimismo, se evidencia que la mayoría de casos de incesto pueden a la vez ser interpretados como casos de violación; por lo tanto, lo más adecuado sería que el tipo penal de violación -al igual que lo hacen los tipos penales regulados en El Salvador y Guatemalacontemple como una circunstancia agravante el hecho de que el sujeto activo tenga una relación de parentesco con la víctima. Sobre todo, porque tal como está configurado actualmente el delito de incesto, este conlleva una pena menor que la violación especial, siendo necesario que la consecuencia jurídica regulada por legislación penal hondureña también sea acorde con el desvalor de la acción del sujeto activo que accede carnalmente a un familiar, vulnerado de esta manera su libertad sexual.

Así, mientras que el acceso carnal sin violencia con un sujeto pasivo mayor de 14 años y menor de 18 años, siendo el sujeto activo el que está encargado de la guarda o custodia de la víctima y valiéndose de su condición de autoridad; si se le acusará por el delito de violación especial se le impondría una pena de 15 a 20 años de prisión. Pero si se interpretara esta conducta como acceso carnal con descendiente mayor de 14 años y menor de 18, la pena a imponer sería de 6 a 9 años de prisión. $Y$ en virtud del principio general favor rei, se deberá de aplicar la ley que sea más benigna a los intereses del imputado (Tribunal Primero de Sentencia de Santa Ana, 2002). En definitiva, la confusa regulación jurídica penal de ambos delitos -violación e incesto- puede generar una grave afectación en los derechos de la víctima, y podría incluso ser considerado como un "incentivo" al sujeto activo que accede carnalmente a un familiar en detrimento de su libertad o indemnidad sexual.

En relación con el Artículo 144, el cual regula el delito de rapto, si bien este ha sufrido cambios significativos, su sanción también resulta cuestionable. Así, el tipo penal establece que, quien con fines de carácter sexual y mediante fuerza, intimidación o engaño, sustrajere o retuviere a una persona, será sancionado con reclusión de cuatro a seis años; y cuando la víctima sea una persona menor de dieciocho años de edad, la sanción se aumentará en un medio de la pena. Tal como afirmábamos supra, se han realizado importantes reformas al delito de rapto. Por ejemplo, anteriormente el Artículo 151 del Código Penal hondureño contemplaba la exención de la pena para quien se casara posteriormente con la víctima de rapto o estupro (Pérez Munguía, 2012). No obstante, consideramos que este tipo de conducta también podría encajarse en el delito de privación de libertad, regulado en el Artículo 193 del Código Penal, el cual regula que, quien prive injustamente a otro de su libertad -fuera de los supuestos del delito de secuestro- ${ }^{49}$ será sancionado con

49 El Artículo 192 regula el delito de secuestro así: Será sancionado con la pena de reclusión de veinte (20) años a privación de la libertad de por vida, aun cuando no consiguiere su propósito, quien con violencia, 
reclusión de tres a seis años. Asimismo, el Artículo 194 establece que para este delito serán consideradas como circunstancias agravantes el hecho de que el delito se cometa en persona menor de edad (núm. 1), si la privación de la libertad se prolonga por más de veinticuatro horas (núm. 2), cuando existan amenazas o trato cruel para la persona secuestrada (núm. 5), entre otras circunstancias; supuestos similares a los contemplados en el delito de rapto.

Consideramos más adecuado trasladar al delito de privación de libertad a los supuestos del actual delito de rapto, adaptándose la pena al desvalor de la acción, debido a que en los supuestos de rapto, se afecta algo más que la libertad sexual de la víctima, dado que el sujeto activo, que no obstante sustrae y retiene a una persona con fines principalmente de naturaleza sexual, con su acción también limita

intimidación, engaño u otra forma que vicie el consentimiento, sustraiga, retenga, desplace, oculte o prive de cualquier otra manera de su libertad a una o más personas, con cualesquiera de los propósitos siguientes:

a) Obtener a cambio de la libertad de la o las personas secuestradas, dinero, bienes, titulo u otra utilidad o beneficio;

b) Obligar a alguien a que haga o deje de hacer algo; y

c) Publicitarios o políticos.

De Concurrir algunas de la circunstancia siguiente, la pena aplicable será de:

1. Cuarenta (40) años de reclusión a privación de libertad de por vida si se ocasionare o diere lugar a la muerte del secuestrado;

2. Treinta (30) años de reclusión a privación de libertad de por vida si el secuestrado, o cualquier otra persona muriere con motivo del proceso de rescate.

Si los secuestradores desistiesen liberando a la víctima y no hubieren obtenido el precio reclamado, la pena aplicable será de diez (10) a veinte (20) años de reclusión.

Si con motivo de la liberación muriesen miembros de la seguridad o cualquier otra persona que intervenga, se aplicará en el numeral 2 de este Artículo.

Con la misma pena establecida en el numeral 2, rebajada la pena mínima en un tercio $(1 / 3)$, se sancionará a los responsables, si con motivo del proceso de rescate, la víctima o cualquier otra persona sufriese lesiones. a la víctima no solo en esta manifestación de la libertad, sino que también afecta a su libertad ambulatoria. Asimismo, tal como manifestábamos supra, consideramos necesario eliminar la referencia al rapto, puesto que este tipo de delitos están más vinculados con la idea del "pudor" o el "honor" de la persona raptada.

Finalmente, el Capítulo I regula el delito de hostigamiento sexual en los Artículos 147-A, 147B y 147-C. Así, el Artículo 147-A regula como tipo básico de hostigamiento sexual la conducta en la cual el sujeto activo por sí o un tercero, valiéndose de una situación de superioridad, cause en la víctima represalias por rechazo de actos indecorosos realizados por medio de insinuaciones o solicitud de favores de carácter sexual, para sí o para un tercero, concurriendo cualesquiera de las circunstancias siguientes:

1) Valiéndose de una situación de superioridad jerárquica laboral o administrativa, cause inestabilidad, descalificación en el desempeño de su trabajo o ventaja o desventaja para ascensos laborales, o impida el acceso a un puesto de trabajo;

2) Valiéndose de una situación de superioridad jerárquica docente, cause inestabilidad, descalificación de sus estudios, ofrezca la aprobación o reprobación indebida de pruebas, exámenes o grados o cualquier otra condición que influya determinantemente en su condición de estudiante; y

3) Valiéndose de una situación de superioridad jerárquica religiosa, cause inestabilidad personal o familiar u ofrezca bienestar espiritual. 
La sanción a imponer al sujeto activo de este delito será de reclusión de tres a seis años y de inhabilitación especial por el tiempo que dure la condena. Asimismo, el inciso final del referido Artículo establece que la pena se incrementará en un tercio cuando la conducta sea cometida en perjuicio de niños o niñas, o de personas que adolezcan de enfermedades mentales.

Si bien este tipo penal también ha sufrido importantes reformas, algunas de las críticas realizadas siguen vigentes. Así, Pérez (2012) señalaba que el tipo penal contiene supuestos de hecho difíciles de probar -por ejemplo "inestabilidad laboral"- lo cual ha dificultado la aplicación del tipo penal. Asimismo, el autor criticaba la exigencia del tipo penal en cuanto que, para que este se configure, debe existir una relación jerárquica entre el sujeto activo y el sujeto pasivo, aun cuando es posible que el hostigamiento sexual se dé también entre pares. Posiblemente, por estas críticas es que el legislador hondureño decidió añadir, mediante Decreto 35-2013,50 el artículo 147-B, que sanciona el hostigamiento sexual que se produzca sin que medie superioridad jerárquica, con una pena atenuada de dos a cuatro años de reclusión y de inhabilitación especial por el tiempo que dure la condena.

Asimismo, mediante el mismo Decreto 352013 se añadió al Código Penal el Artículo 147-C, que sanciona al sujeto activo de hostigamiento sexual cuando haya utilizado medios electrónicos, de telecomunicación o tecnologías de la información para cometer la

50 Decreto 35-2013 de fecha 27 de febrero de 2013, publicado en el Diario Oficial La Gaceta No.32, 222 de fecha 6 de septiembre de 2013 y vigente a partir de dicha publicación. conducta típica. La pena establecida para este tipo especial agravado es de tres a seis años de reclusión e inhabilitación especial por ese mismo periodo, cuando proceda. Además, la pena se incrementará en un tercio cuando sea cometido en perjuicio de niños y niñas o de personas que adolezcan de enfermedades mentales.

En cuanto a las consecuencias accesorias reguladas para los delitos regulados por este Capítulo, el Artículo 153 del Código Penal establece que los reos serán también condenados por vía de indemnización a estas obligaciones:

1) Proveer alimentos a la ofendida y a los concebidos como consecuencia de la relación sexual, en su caso;

2) Reconocer a los concebidos como consecuencia de la relación sexual, salvo oposición de la madre; e

3) Indemnizar por los costos del tratamiento médico o psicológico, terapia y rehabilitación física y ocupacional por perturbación emocional, dolor, sufrimiento y cualquier otra pérdida sufrida por la víctima.

En cuanto a los delitos regulados en el Capítulo II Delitos de explotación sexual comercial, del Título en estudio, en conformidad con el Artículo 154-A del Código Penal, aquí se contienen aquellos delitos que conllevan la utilización de personas en actividades con fines sexuales donde existe un pago o promesa de pago para la víctima o para un tercero que comercia con ella. ${ }^{51}$ Así, este Capítulo regula los delitos de

51 Esta es la misma definición que hace la Ley Contra la Trata de Personas en el Artículo 6, núm. 10. 
proxenetismo, determinación a la prostitución, pornografía infantil y turismo sexual. En cuanto a la regulación del delito de proxenetismo, el tipo básico se encuentra sancionado en el inciso primero del Artículo 148 del Código Penal hondureño con una pena de reclusión de seis a diez años y multa de cien a doscientos salarios mínimos ${ }^{52}$ para quien promueva, induzca, facilite, reclute o someta a otras personas en actividades de explotación sexual comercial; y el inciso segundo del Artículo en mención contiene el subtipo agravado, conllevando el aumento de la sanción del tipo básico en un medio de la pena cuando el proxenetismo se realice en víctimas menores de dieciocho años; cuando la víctima sea sometida a condiciones de servidumbre $u$ otras prácticas análogas a la esclavitud; cuando el sujeto activo se aproveche de su oficio, profesión o negocio, o ejerza una relación de poder por razón de confianza, parentesco o jerarquía sobre la víctima.

Asimismo, el Artículo 149-A sanciona la inducción o favorecimiento de la explotación sexual comercial de personas menores de dieciocho años, con pena de reclusión de tres a seis años y multa de cincuenta a cien salarios mínimos. De igual forma, el Artículo 149B castiga la utilización de personas menores de dieciocho años de edad en exhibiciones o espectáculos públicos o privados de naturaleza sexual, con pena de reclusión de cuatro a ocho años y multa de cien a doscientos salarios mínimos. Y el Artículo 149-C sanciona el acceso

52 De conformidad con el artículo 154-B del Código Penal hondureño, las multas del Título II del referido Código, fijadas en salarios, se calcularán tomando como base el salario mínimo mensual en su escala mayor según la región y la actividad económica de la zona. Para ver el salario mínimo vigente para el año 2015 consultar el Acuerdo n. ${ }^{\circ}$ STSS-599-2013 disponible en http://www.trabajo. gob.hn/organizacion/dgt-1/direccion-general-de-salarios/decretos/ Acuerdo\%20STSS-599-2013.docx/view carnal o actos de lujuria con personas mayores de catorce o menores de dieciocho años de edad, realizados a cambio de pago o cualquier otra retribución en dinero o especie a la persona menor de edad o a una tercera persona, con una pena de seis a diez años de reclusión.

Vinculado a las conductas anteriores está la regulada en el Artículo 149-E, que sanciona el turismo sexual, descrito este por el tipo penal como la conducta de atraer la afluencia de turistas a través de la promoción o realización de programas publicitarios o campañas de todo tipo, haciendo uso de cualquier medio para proyectar el país a nivel nacional e internacional, como un destino turístico accesible para el ejercicio de actividades sexuales con personas de uno $u$ otro sexo. La pena a imponer al sujeto activo de este delito es de reclusión de ocho a doce años más multa de ciento cincuenta a doscientos cincuenta salarios mínimos; agravándose la pena en un medio cuando las víctimas sean personas menores de dieciocho años de edad y cuando el autor se valga de ser funcionario o autoridad pública en servicio.

Tal como apuntábamos supra, el Artículo 154A establece que se entenderá por explotación sexual comercial la utilización de personas en actividades con fines sexuales donde existe un pago o promesa de pago para la víctima o para un tercero que comercia con ella. Dada esta definición establecida por el legislador penal hondureño -sobre todo en el caso de personas mayores de edad-, puede existir dificultad de determinar cuándo estaremos ante casos de explotación sexual comercial y cuándo ante casos de ejercicio de la prostitución, puesto que la prostitución o trabajo comercial del sexo no 
está penada por la legislación hondureña..$^{53} \mathrm{En}$ este sentido, Pérez (2012) advierte que si bien el ejercicio de la prostitución -o trabajo sexuales una cuestión "bastante polémica en nuestra sociedad" (p. 56); no obstante, el movimiento de trabajadores/as del sexo en otras sociedades han manifestado que el abolicionismo tampoco es una propuesta posible en nuestro tiempo, puesto que la historia ha demostrado que en esas épocas de prohibiciones y clandestinidad cuando más prosperan las mafias de explotación sexual comercial.

En cuanto a las consecuencias accesorias reguladas para los delitos regulados por este Capítulo, el Artículo 153, inciso final del Código Penal, establece que los reos serán también condenados a indemnizar por los costos del tratamiento médico o psicológico, terapia y rehabilitación física y ocupacional por

53 Incluso la Ley de Policía y Convivencia Social en su Artículo 85 establece que la reglamentación sobre la prostitución que emitan las municipalidades y las Secretarías de Salud y Gobernación deberá realizarse dentro del más amplio respeto a la dignidad y derechos humanos de las personas que ejerzan esta actividad y con el sólo propósito de preservar la salud, el orden y la seguridad sin sujeción a registro de ningún género. Ley disponible en http:// www.poderjudicial.gob.hn/CEDIJ/Leyes/Documents/LEY\%20 DE\%20POLIC\%C3\%8DA\%20Y\%20CONVIVENCIA\%20 CIUDADANA\%20\%2809\%29.pdf

Asimismo, en la Ley Especial sobre VIH/SIDA se establece en el Artículo 30, como medida de control sanitario y epidemiológico, que las personas que se dediquen al comercio sexual tienen la obligación de presentarse al centro de salud para ser registradas y examinadas, así como recibir educación sobre prevención de la infección por VIH y otras enfermedades de transmisión sexual, y deberán realizarse el control médico sanitario previo a la obtención de su respectivo Certificado de Salud Sanitario. En opinión de Pérez (2012), al confrontar la disposición del Artículo 30 de la Ley Especial sobre VIH/SIDA con el Artículo 85 de la Ley de Policía y Convivencia Social, se produce una antinomia, sugiriendo el autor que se resuelva dicha contradicción con el principio lex posterior derogat prior; por la tanto, deberá prevalecer la Ley de Convivencia. Añade el autor que la disposición analizada de la Ley Especial sobre VIH/SIDA "pareciera reforzar una concepción preventiva, ya superada, de 'grupos de riesgo', frente a la menos estigmatizadora de 'conductas de riesgo"'. Pérez (2012), pp. 54-55. perturbación emocional, dolor, sufrimiento y cualquier otra pérdida sufrida por la víctima.

Finalmente, el Capítulo III del Título en estudio contiene disposiciones generales. Así, el Artículo 152 establece que en los delitos comprendidos en el Título se procederá mediante acción pública ejercida por el Ministerio Público de oficio o a instancia de parte interesada, cuando las víctimas fueren personas menores de dieciocho años de edad; al igual que en los delitos de violación y de explotación sexual comercial, incluso cuando la víctima fuere mayor de dieciocho años de edad. Asimismo, el inciso final del Artículo en estudio establece que en los demás delitos comprendidos en el Título, cuando la víctima fuere mayor de edad, se procederá en virtud de querella. De igual forma, el Artículo 154 establece que serán penados como autores, los ascendientes, tutores, maestros, o cualesquier persona que, con abuso de autoridad o encargo, cooperaren como cómplices en la perpetración de delitos comprendidos en el Título en estudio.

Otra ley que es válida de destacar es la Ley Contra la Trata de Personas, ${ }^{54}$ que aborda la problemática de la trata de personas con un enfoque integral, haciendo énfasis en la prevención, combate y atención a las víctimas de trata de personas. En relación con la violencia sexual, la citada Ley, en su Artículo 6 núm. 6 define al embarazo forzado como "la acción de inducir a una mujer por fuerza, engaño $u$ otro medio de violencia a quedar en estado de embarazo, con la finalidad de la venta de la persona menor de edad, producto del mismo".

54 Aprobada por Decreto n.o 59-2012 de fecha 25 de abril de dos mil doce. 
De igual forma, el núm. 7 del Artículo en comento establece que el matrimonio forzado o servil se produce -entre otros supuestoscuando una persona contrae matrimonio bajo engaño y es sometida a servidumbre sexual y/o laboral. Finalmente, el núm. 10 del mismo Artículo -y en línea con el Artículo 154-A del Código Penal- define la explotación sexual comercial como "La utilización de personas en actividades con fines sexuales donde existe un pago o promesa de pago para la víctima o para un tercero que comercia con ella”.

En cuanto a las disposiciones penales contenidas en la Ley, el Artículo 52 sanciona como reo del delito de trata de personas a: "Quien facilite, promueva o ejecute la captación, la retención, el transporte, el traslado, la entrega, la acogida o la recepción de personas, dentro o fuera del territorio nacional, para someterlas a servidumbre, esclavitud o sus prácticas análogas, trabajos o servicios forzosos, mendicidad y embarazo forzado, matrimonio forzado o servil, tráfico ilícito de órganos, fluidos y tejidos humanos, venta de personas, explotación sexual comercial, adopción irregular y el reclutamiento de personas menores de dieciocho (18) años para su utilización en actividades criminales y será sancionado con pena de diez (10) a quince (15) años de reclusión, más inhabilitación absoluta por el doble del tiempo que dure la reclusión y multa de ciento cincuenta (150) a doscientos cincuenta (250) salarios mínimos”.

Este mismo Artículo regula un subtipo agravado en un medio de la pena del tipo básico en los siguientes supuestos:
1) Cuando la víctima sea menor de dieciocho (18) años de edad;

2) Cuando el autor sea cónyuge, conviviente o pariente de la víctima hasta el tercer grado de consanguinidad o segundo de afinidad;

3) Cuando el sujeto activo haga uso de fuerza, intimidación, engaño, promesa de trabajo o le suministre drogas o alcohol a la víctima;

4) Cuando el sujeto activo se aprovecha de su negocio, oficio, profesión o función que desempeña;

5) Cuando el sujeto activo se aprovecha de la relación de confianza con las personas que tienen autoridad sobre la víctima o hace pagos, préstamos o concesiones para obtener su consentimiento;

6) Cuando el hecho punible fuese cometido por un grupo delictivo integrado por tres (3) o más miembros; $\mathrm{y}$

7) Cuando la víctima en razón del abuso al que es sometida, queda en estado de discapacidad o contrae una enfermedad que amenace su vida.

El inciso final del Artículo en comento establece la nulidad del consentimiento otorgado por la victima de Trata de Personas o por su representante legal. Al respecto de esta especial mención en el tipo penal, consideramos que en los casos regulados en el tipo penal existe una imposibilidad de consentir la propia explotación sin que haya una causa que determine el vicio de dicho consentimiento, tales como el abuso de autoridad, de una situación de vulnerabilidad o la concesión o recepción de pagos o beneficios 
para obtener el consentimiento de una persona que tenga autoridad sobre la víctima; puesto que incluso en estos supuestos la voluntad está doblegada de antemano, dada la clara restricción del ámbito de determinación de la víctima (Bolaños, 2013).

Ante la imposibilidad de dar un consentimiento válido cuando se utilizan medios coercitivos para explotar a una persona, algunos autores han llegado incluso a cuestionar si es necesario especificar la invalidez del consentimiento en el tipo penal de trata de personas (Naciones Unidas, 2006; Manzanares, 2010). Así, Roxin (2008) manifiesta que en los tipos que presuponen una cooperación de la víctima y que sirven para su protección -lo cual sería aplicable para el delito de trata de personasse hace caso omiso del consentimiento de la víctima porque, con una presunción irrefutable, el legislador le deniega desde el principio la facultad para una libre y responsable decisión. Mientras que Martínez Osorio considera que resulta difícil concederle efectos destipificadores a la "libre voluntariedad" de la víctima de trata, cuando existe detrás todo un aparato de control y presión sobre esta, como acontece en la explotación sexual comercial organizada; por tanto, el consentimiento en tales coordenadas será un aspecto muy discutible (Martínez, 2008).

En definitiva, los casos en los cuales se podría dar un consentimiento válido por parte de la víctima de trata son prácticamente imposibles, primero porque difícilmente el tratante dirá a la víctima las verdaderas intenciones de explotarla; segundo, porque también será difícil encontrar una persona que acceda a su propia explotación sin mediar medios que vicien el consentimiento, así, aún en el caso de que la víctima consintiera su propia explotación, debe verificarse que no existe una situación de vulnerabilidad o especial necesidad que la impulsara a aceptar su trata con fines de explotación (Bolaños, 2013).

Entre los aspectos positivos que contiene esta Ley está el hecho de que el Artículo 46 establece que el delito de trata de personas es de acción pública. Asimismo, el Artículo 47 regula la no punibilidad penal o administrativa de las víctimas de trata por infracciones cometidas por estas durante la ejecución de la actividad delictiva de trata y como consecuencia de esta.

Finalmente, el Código de la Niñez y la Adolescencia, en el Artículo 134 tipifica el delito de explotación económica, sancionando con pena de reclusión de tres a cinco años a quien -entre otros supuestos- promueva, incite o haga que un niño realice actividades deshonestas, tales como la prostitución, la pornografía, la obscenidad y la inmoralidad. ${ }^{55}$ En relación a los tipo penales regulados tanto en la Ley Contra la Trata de Personas como en Código de la Niñez y la Adolescencia -en línea con lo recomendado por Pérez (2012)- y en concordancia con el principio de legalidad penal, se sugiere que estos tipos penales se incorporen al Código Penal, debido a que, por el contenido heterogéneo tanto de la Ley contra la Trata de Personas como del Código de la Niñez y la Adolescencia, estas no puede ser considerada leyes penales especiales. 


\section{Discusión}

Tras el análisis de los tipos penales que protegen la libertad y la indemnidad sexual en la legislación hondureña, podemos apuntar los siguientes aspectos. En primer lugar, consideramos que se han realizado importantes reformas a la legislación penal en cuanto a los bienes jurídicos en estudio. No obstante, aún hay aspectos importantes a considerar. Entre estos aspectos podemos mencionar la denominación del Capítulo I del Título II Libro II Parte Especial del Código Penal, que hace referencia a los delitos de violación, estupro, ultraje al pudor y rapto. Consideramos que dicha denominación debería reformarse, siendo más conveniente hacer referencia a los bienes jurídicos protegidos en los delitos de violencia sexual, a saber: la libertad y la indemnidad sexual de las personas, logrando, asimismo, eliminar los problemas de interpretación o significación que generan los conceptos "pudor" o "rapto".

En cuanto a la regulación del delito de violación -artículo 140- consideramos que la restricción hecha por el legislador en el tipo penal en relación al tipo de amenaza que debe recibir el sujeto pasivo, en cuanto a que dicha amenaza debe estar dirigida hacia la víctima o su cónyuge o compañero de hogar, o a uno de sus parientes dentro del cuarto grado de consanguinidad o segundo de afinidad, dicha restricción no nos parece adecuada, en tanto que el sujeto pasivo también podría recibir otro tipos de amenazas para acceder a una relación sexual no consentida, por ejemplo, amenazas de ocasionar un perjuicio grave e inminente a una tercera persona con la que no se posea un vínculo de los establecidos en el tipo penal. Asimismo, deberían contemplarse dentro del tipo penal los supuestos de amenazas de fuerza sobre las cosas. En definitiva, lo que sería importante considerar en estos casos es que la amenaza efectuada a la víctima posea la entidad suficiente como para provocar que esta acceda a la relación sexual, en tanto que dicha amenaza ponga en peligro la tranquilidad de la víctima y su libertad de decisión.

En referencia la regulación del delito de lujuria -Artículo 141- consideramos que el tipo penal es impreciso al determinar la conducta típica que debe cometer el sujeto activo, dado que no contiene verbos rectores claros, lo cual representa una vulneración al principio de legalidad, además de dejar al criterio interpretativo del juez qué se debe entender por "actos de lujuria". Asimismo, se realiza la misma crítica en el delito de violación en cuanto a la limitación en el tipo de amenazas que debe sufrir el sujeto pasivo para que se configure el tipo penal. Similar situación sucede con el Artículo 142, el cual contiene el tipo penal de estupro, y también carece de descripción de la conducta típica en el tipo penal. Por lo tanto, se recomienda dotar de contenidos claros a ambos tipos penales, en apego con el principio de legalidad penal.

En relación con la regulación hecha en el Artículo 143 para el delito de incesto, nos resulta cuestionable la regulación del subtipo agravado, establecida para la conducta de incesto recaída en sujeto pasivo mayor de catorce y menor de dieciocho años de edad, en tanto que consideramos que esta conducta típica también podría encajarse en la conducta típica del delito de violación, por ejemplo, en el supuesto de que el sujeto activo tuviese acceso carnal con descendiente, hermano/a, adoptado/a, puede coincidir que a la 
vez el sujeto activo sea el encargado de la guarda o custodia del sujeto pasivo y se valga de su condición de autoridad para tener acceso carnal con este, configurándose a su vez el delito de violación agravada estipulado en el artículo 104 núm. 4. Similar situación sucede cuando el sujeto activo tuviese acceso carnal con ascendiente, hermano/a, adoptante, madrastra o padrastro mayor de setenta 70 años, en el sentido de que también se configuraría el supuesto regulado en el Artículo 140 inciso final, si el acceso carnal se ejecutare con violencia o intimidación.

Pero, dado que el Artículo 143 regula como condición de procesabilidad que la parte ofendida inicie la querella, podría estarse favoreciendo la impunidad de atentados contra la indemnidad y libertad sexual, cuando la víctima del delito de incesto no acuda a denunciar por temor al sujeto activo y, en estos casos -que podrían ser propios delitos de violación más que de incesto- tampoco una tercera persona podría interponer la querella, ni el Ministerio Público podría actuar de oficio. De igual forma, la actual regulación del delito de incesto podría incluso llegar a ser considerada como un "incentivo" al sujeto activo que accede carnalmente a un familiar en detrimento de su libertad o indemnidad sexual. Así, mientras que el acceso carnal sin violencia con un sujeto pasivo mayor de 14 años y menor de 18 años, siendo el sujeto activo el que está encargado de la guarda o custodia de la víctima y valiéndose de su condición de autoridad, si se le acusará por el delito de violación especial se le impondría una pena de 15 a 20 años de prisión. Pero si se interpretará esta conducta como acceso carnal con descendiente mayor de 14 años y menor de 18, la pena a imponer sería de 6 a 9 años de prisión. Y en virtud del principio general favor rei, se deberá aplicar la ley que sea más benigna a los intereses del imputado. En definitiva, la confusa regulación jurídica penal de ambos delitos -violación e incesto- puede generar una grave afectación en los derechos de la víctima, por lo que recomendamos suprimir el tipo penal de incesto y establecer dentro de los supuestos de violación especial que la víctima tenga una relación de parentesco con la víctima, tal como ya lo hacen las regulaciones de E1 Salvador y Guatemala.

De igual forma, consideramos que la condición de procesabilidad estipulada por el Artículo 143 no es congruente con la configuración del tipo penal, en cuanto que si se exige que la parte ofendida inicie la querella, de esta condición se infiere que la persona que acude al Ministerio Público a denunciar que ha sido víctima del delito de incesto, se siente atacada y/o vulnerada en su libertad sexual. En definitiva, estaríamos ante casos en los que el acceso carnal se ha realizado sin el consentimiento de la víctima, pues de otra forma no acudiría a denunciar.

En relación con el Artículo 144, el cual regula el delito de rapto, si bien este ha sufrido cambios significativos, su sanción también resulta cuestionable. Así, consideramos que este tipo de conducta también podría encajarse en el delito de privación de libertad, regulado en el Artículo 193 del Código Penal, que regula como conducta típica el privar a otro injustamente de su libertad, fuera de los supuestos del delito de secuestro. Consideramos más adecuado trasladar al delito de privación de libertad a los supuestos del actual delito de rapto, adaptándose la pena al desvalor de la acción, debido a que en los supuestos de rapto, se afecta algo más que la libertad sexual de la víctima, dado que el 
sujeto activo que sustrae y retiene a una persona con fines principalmente de naturaleza sexual, con su acción también limita a la víctima no solo en esta manifestación de la libertad, sino que también afecta a su libertad ambulatoria. Asimismo, tal como manifestábamos supra, consideramos necesario eliminar la referencia al rapto, puesto que este tipo de delitos están más vinculados con la idea del "pudor" o el "honor" de la persona raptada.

En lo que respecta al Capítulo II Delitos de explotación sexual comercial, y en especial a la definición de explotación sexual comercial que señala el Artículo 154-A, nos parece que dicha definición -principalmente en el caso de personas mayores de edad- puede existir dificultad de determinar cuándo estaremos ante casos de explotación sexual comercial y cuándo ante casos de ejercicio de la prostitución, ya que dicha definición podría dar lugar a interpretar que el pago o promesa de pago hecho a una persona sin la intervención de intermediarios también constituye una conducta de explotación sexual comercial.

Esta definición de explotación sexual comercial se encuentra muy vinculada con la Ley Contra la Trata de Personas, que hace referencia a la invalidez del consentimiento dado por la víctima de trata. Al respecto, consideramos que los casos en los cuales se podría dar un consentimiento válido por parte de la víctima de trata son prácticamente imposibles; primero, porque difícilmente el tratante dirá a la víctima las verdaderas intenciones de explotarla; y segundo, porque también será difícil encontrar una persona que acceda a su propia explotación sin mediar medios que vicien el consentimiento, así, aún en el caso de que la víctima consintiera su propia explotación, debe verificarse que no existe una situación de vulnerabilidad o especial necesidad que la impulsara a aceptar su trata con fines de explotación. En definitiva, si bien la legislación hondureña es clara al establecer que una víctima de trata de personas no puede prestar un consentimiento válido, no obstante dicha legislación es ambigua a la hora de regular el ejercicio de la prostitución.

Finalmente, en cuanto a las otras leyes secundarias que contienen tipos penales relacionados con la protección de la libertad e indemnidad sexual, a saber: La Ley Contra la Trata de Personas y el Código de la Niñez y la Adolescencia, nos parece positivo que ambas legislaciones cuentan con un enfoque integral, yendo más allá del mero enfoque punitivo. No obstante, por esta misma razón, se sugiere que los tipos penales regulados en dichos cuerpos normativos se incorporen al Código Penal, debido a que, por el contenido heterogéneo tanto de la Ley contra la Trata de Personas como del Código de la Niñez y la Adolescencia, estas no pueden ser consideradas como leyes penales especiales.

\section{Referencias}

Antony, C. (marzo-abril de 2007). Mujeres invisibles: las cárceles femeninas en América Latina. Nueva Sociedad (208), 73-85.

Arroyo, R. (2001). Aplicabilidad de la normativa sobre la violencia contra la mujer en Centroamérica. Madrid: Universidad Carlos III de Madrid. 
Asociadas por lo Justo [JASS]; Centro de Derechos de Mujeres [CDM]; Centro de Estudios de la Mujer-Honduras [CEMH], Foro de Mujeres por la Vida y Red Nacional de Defensoras de Derechos Humanos de Honduras. (2014). Informe de Organizaciones Feministas ante la Relatora Especial de Naciones Unidas sobre Violencia contra la mujer, sus causas y consecuencias. Tegucigalpa: Autores.

Bähr, K. (2005). Violencia contra las mujeres y seguridad en Honduras. Un estudio exploratorio. Tegucigalpa: Instituto Universitario en Democracia, Paz y Seguridad.

Bolaños, H. J. (2013). La regulación jurídicopenal de la trata de personas. Especial referencia a El Salvador y España. San Salvador: UTEC.

Bott, S., Guedes, A., Goodwin, M., \& Adams, J. (2013). Resumen del Informe Violencia contra la mujer en América Latina y el Caribe: Análisis comparativo de datos poblacionales de 12 países. Washington, DC: OPS.

Bradshaw, S., \& Arenas, Á. (2004). Análisis de género en la evaluación de los efectos socioeconómicos de los desastres naturales. Santiago de Chile: Naciones Unidas.

Carcedo, A. (2012). Primera medición del Sistema de indicadores para evaluar desde la sociedad civil el cumplimiento estatal de la Convención de Belém do Pará. San José: Instituto Interamericano de Derechos Humanos.
Carías, A. (2011). Violencia contra las mujeres y misoginia: una relación indisoluble (Primera ed.).(H.Teruel Fernández, Ed.) Tegucigalpa: Centro de Derechos de Mujeres.

Caruso, M. V. (2006). Nuevas perspectivas sobre los delitos contra la libertad sexual. Tirant online.

Centro de Derechos de Mujeres. (2005). Violencia contra las mujeres en Honduras: Una reflexión en el camino (Primera ed.). Tegucigalpa: Autor.

Centro de Derechos de Mujeres. (2012). Como las siemprevivas, vivas y fuertes, nunca vencidas. Estudio sobre violencia doméstica contra mujeres jóvenes de los municipios de Santa Rosa de Copán y Nueva Arcadia, Departamento de Copán, Honduras. Tegucigalpa: Autor.

Comisión Interamericana de Derechos Humanos. (2009). Honduras: derechos humanos y golpe de estado. Washington D.C.: OEA.

Comisión Interamericana de Mujeres. (2012). Integración de la perspectiva de género y de derechos en la gestión integral de riesgos de desastres en las Américas. Washington D.C.: OEA.

Comité de América Latina y el Caribe para la Defensa de los Derechos de la Mujer [CLADEM]. (2007). Monitoreo sobre violencia sexual en conflicto armado. (Primera ed.). Lima: Autor. 
Dammert, L., \& Zúñiga, L. (2008). La cárcel: problemas y desafíos para las Américas. Santiago de Chile: FLACSO.

Dinys, L., \& Padilla, K. (2012). Violencia sexual en El Salvador, Guatemala, Honduras y Nicaragua: Análisis de datos primarios y secundarios (Primera ed.). Managua: Ipas Centroamérica.

Foro Internacional de Mujeres Indígenas. (2006). Mairin Iwanka Raya: New Beginnings for Women, Miskito. New York: Autor.

Goenaga, R. (Octubre de 1997). Delitos contra la libertad sexual. Eguzkilore (Número Extraordinario 10), 95 - 120.

Jareño, Á. (2010). Delitos contra la Libertad: Las amenazas. En J. Boix Reig (Ed.), Derecho Penal Parte Especial (págs. 225-241). Madrid: Iustel.

Manzanares, J. L. (2010). Código Penal (Comentarios y jurisprudencia) Parte Especial (Vol. V). Granada: Comares.

Martínez, M. A. (2008). El delito de trata de personas en el Código Penal. San Salvador: Consejo Naciona de la Judicatura.

Monge, A. (2005). Los delitos de agresiones sexuales violentas (Análisis de los artículos 178 y 179 CP conforme a la LO 15/1995, de 25 de noviembre). Tirant online.

Moreno, C. (2014). La prevención de la violencia contra las mujeres y las niñas el contexto educativo. Panamá: UNICEF.
Muñoz, D. (2011). Análisis sobre el Marco Jurídico Legal para la atención a las Victimas Sobrevivientes de Violencia Sexual. Managua: IPAS Centroamérica.

Naciones Unidas. (2006). Integración de los derechos humanos de la mujer y la perspectiva de género. Informe de la Relatora Especial sobre los derechos humanos de las víctimas de la trata de personas, especialmente mujeres y niños, Sra. Sigma Huda. Consejo Económico y Social.

Observatorio de Derechos Humanos de las Mujeres. (Febrero de 2014a). Violencia contra las mujeres hondureñas. Recuperado el 30 de enero de 2015, de http://www. derechosdelamujer.org/tl_files/documentos/ violencia/Misoginia-armada-2013.pdf

Observatorio de Derechos Humanos de las Mujeres. (Marzo de 2014b). Violencias contra las mujeres en 2013: lo que dice la prensa nacional. Recuperado el 31 de enero de 2015, de http://www.derechosdelamujer. org/t1_files/documentos/violencia/ boletin2013.pdf

Palacios, J. R. (2008). El abuso sexual a niños, niñas y adolescentes: un secreto familiar, un problema social. Revista Electrónica Educare, XII(Extraordinario), 99-111.

Pérez, A. (2012). Propuesta para la armonización del marco legal hondureño con la normativa internacional en materia de violencia contra las mujeres. Tegucigalpa: Instituto Nacional de la Mujer. 
Quintano, A. (1962). Tratado de la Parte especial del Derecho penal (Primera ed., Vol. I). Madrid: Rev. de Derecho privado.

Rodríguez, J. A. (2007). Maras y pandillas, comunidad y policía en Centroamérica. (J. A. Rodríguez Bolaños, Ed.) Guatemala: Demoscopía.

Rodríguez, N., Montes, S. M., \& Moreno, M. (2006). Prevalencia del maltrato infantil. Tegucigalpa: Instituto Universitario en Democracia, Paz y Seguridad.

Roxin, C. (2008). Derecho penal: parte general. (D.-M.Luzón Peña,M. Díaz, \& J.de Vicente Remesal, Trads.) Madrid: Civitas.

Sala de lo Penal de la Corte Suprema de Justicia. (8 de febrero de 2011). Sentencia de Casación. (CP-392-09). Honduras.

Sala de lo Penal de la Corte Suprema de Justicia. (28 de mayo de 2013). Sentencia de Casación CP-484-11. Tegucigalpa.

Santibáñez, M. E. (2010). Algunas consideraciones victimodogmáticas en los delitos sexuales. Ars Boni et Aequi, VI(2), 111-130.

Sistema Regional de Indicadores Estandarizados de Convivencia y Seguridad Ciudadana [SES]. (2011a). Prevalencia de violencia sexual 2088-2011 - Indicadores de Seguridad Ciudadana. Recuperado el 14 de enero de 2015, de http://www.seguridadyregion. com/es/prevalencia-de-violenciasexual-2008-2011.html
Sistema Regional de Indicadores Estandarizados de Convivencia y Seguridad Ciudadana [SES]. (2011b). Tasa de Denuncias de Delitos Sexuales por cada 100mil Hbtes. 2008 a 2013 - Indicadores de Seguridad Ciudadana. Recuperado el 14 de enero de 2015, de http://www.seguridadyregion.com/ es/indicadores/indicadores-de-seguridadciudadana/120-tasa-de-denuncias-dedelitos-sexuales-por-cada-100mil-hbtes2008-a-2010.html

The Assessment Capacities Project [ACAPS]. (2014). Otras Situaciones de Violencia en el Triángulo del Norte Centroamericano. Ginebra: Autor.

Tribunal de Sentencia de Juticalpa. (15 de diciembre de 2008). Olancho, Honduras.

Tribunal Primero de Sentencia: Santa Ana. (30 de noviembre de 2002). Sentencia P020184-00. E1 Salvador.

U.S. Department of State. (2014). Trafficking in Persons Report. Washington D.C.: Autor.

United Nations Office on Drug and Crime. (2015). Crime and criminal justice statistics. Recuperado el 21 de Enero de 2015, de http://www.unodc.org/unodc/en/data-andanalysis/statistics/crime.html

Zamora, A. (22 de noviembre de 2013). Se recrudece violencia sexual del Estado contra las hondureñas. Recuperado el 6 de febrero de 2015, de http://www.rebelion.org/noticia. php?id=177188 